\title{
ALTERNATIVAS TIPOLÓGICAS A LA VIVIENDA CONVENCIONAL
}

\author{
(NEW TYPOLOGY FOR CONVENTIONAL HOUSING)
}

Josep I. de Llorens Durán y Alfons Soldevila Barbosa

Doctores Arquitectos, Profesores de la Escuela de Arquitectura de Barcelona - España
Fecha de recepción: 23 - XII - 94

$193-25$

\section{RESUMEN}

La pobreza del repertorio tipológico de la vivienda contemporánea no se corresponde con la variedad de los usuarios que las necesitan, su poder adquisitivo ni los cambios que requiere su utilización.

La bistoria de la arquitectura culta y popular suministra numerosos ejemplos de tipos de viviendas diferentes, abiertos, flexibles y adaptables, basados en las técnicas locales o los materiales que ban ido apareciendo para la industria de la construcción.

En la actualidad, algunos paîses desarrollan experiencias voluntarias y espontáneas encaminadas a variar y renovar la tipologia de la vivienda. Con este objeto, se presenta un prototipo de vivienda minima adaptable. Se puede utilizar para construir "locales habitables" urbanos destinados al sector de la población que no queda satisfecho con la vivienda convencional.

\section{SUMMARY}

Contemporary housing typology is very poor. It does not cater for the variety of users, their requirements and purchasing power, and the changes they need. The bistory of architecture shows many examples of different kinds of housing typology, flexible dwellings and adaptable building systems based on local and new materials.

Some countries are currently developing voluntaristic or spontaneous experiments aimed at changing and renewing the bousing typology. This is the purpose of the prototype designed by Llorens \& Soldevila: an experimental dwelling with a minimum floor area that is cheap, flexible and adaptable. Several modules are combined to build urban "inhabitable spaces" for people to whom conventional solutions are not suited.

\section{Introducción}

Un análisis de las viviendas existentes actualmente en España y, sobre todo, las que han salido recientemente al mercado, revela muy poca variedad en los tipos, resultando además poco o nada adaptables a las necesidades diversas y cambiantes de muchos de sus destinatarios.

Es sorprendente la poca correspondencia que hay entre la diversidad de usuarios, clasificados según las necesidades de cada uno, y las posibilidades que ofrece el mercado actual. Las viviendas disponibles son caras, presentan pocas variantes y son difíciles de adaptar. Los tipos existentes se reducen al "piso" de 3 ó 4 dormitorios, la casa en hilera, la vivienda unifamiliar aislada en ciudad jardín y también el estudio, que reduce a costa de superficie construida la repercusión del solar. La rigidez de la distribución se agrava con los acabados y las instalaciones, que determinan aún más la manera de usar la vivienda e incrementan su coste, incorporando equipos y complementos a menudo inadecuados o inútiles para el habitante que los va a emplear. 
En cambio, los grupos de población con necesidades específicas son muy diversos. No se trata solamente de inmigrantes, minorías étnicas, viejos, minusválidos, gitanos, negros, magrebíes o enfermos, sino que también se pueden considerar como grupos con necesidades específicas los estudiantes, jóvenes "emancipados", hermanas (o hermanos) solteras, matrimonios sin hijos, matrimonios con muchos hijos, parejas inestables, religiosos, jubilados, transeúntes, solitarios, intelectuales o artistas urbanos, grupos de jóvenes (o no tan jóvenes) profesionales que necesitan vivienda-despacho o vivienda-taller, pequeños comercios y, en general, todos los que no se sienten satisfechos con los tipos de vivienda convencional.
Por ello parece conveniente explorar las posibilidades de variedad y adaptación de la vivienda para adecuarla, no solamente desde el proyecto, sino también desde el uso, a todos los grupos de población.

\section{Antecedentes}

La historia pasada y reciente proporciona ejemplos interesantes de vivienda no convencional o edificios que se podrían reconvertir. Algunos se destinaban o destinan a grupos con necesidades específicas, como las cartujas, madrasas y caravansares (Figs. 1 a 3).
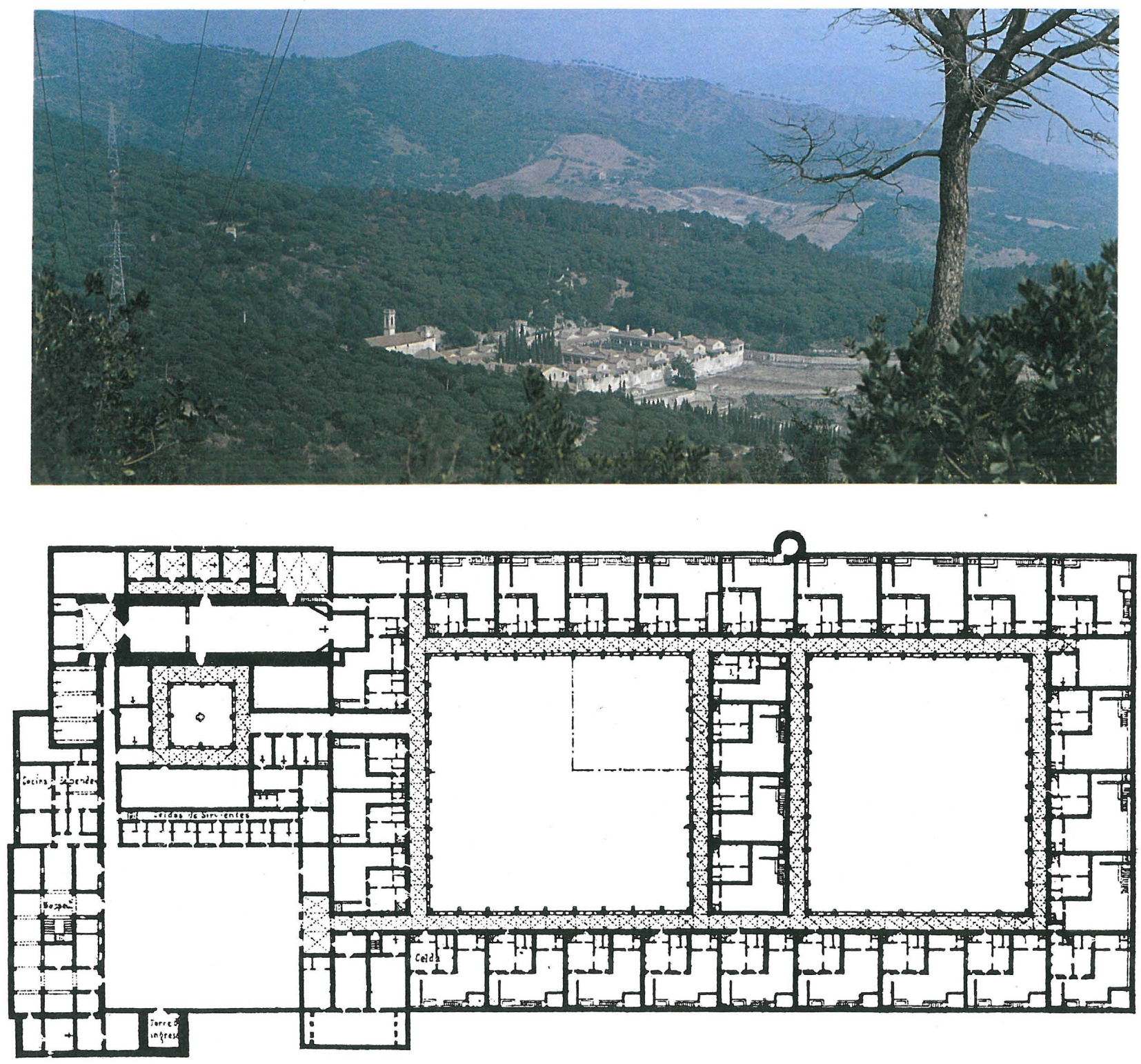

Fig. 1. La Cartuja de Montalegre, Tiana. 


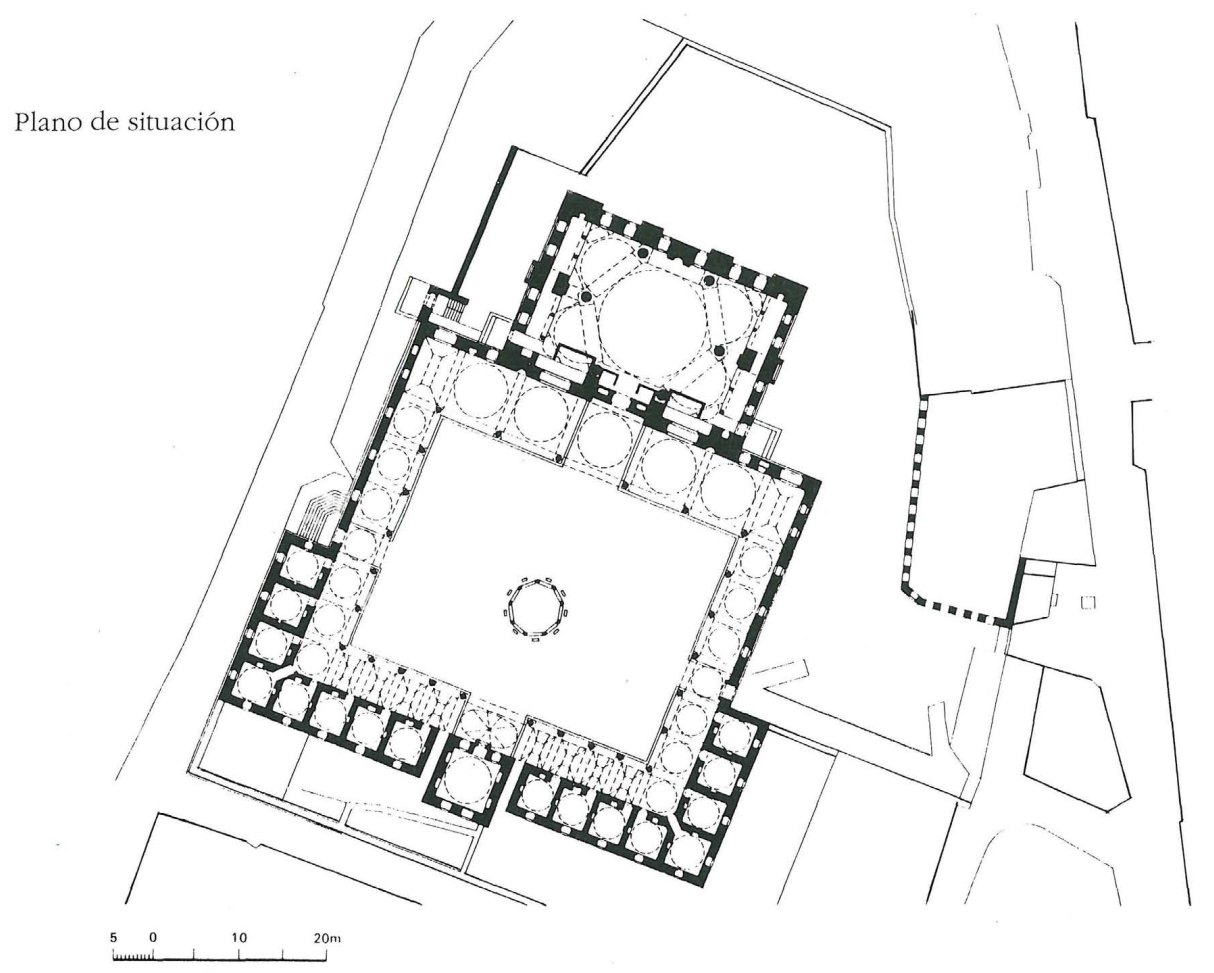

Fig. 2. Madrasa de Abmet Pasha Cami, Estambul.
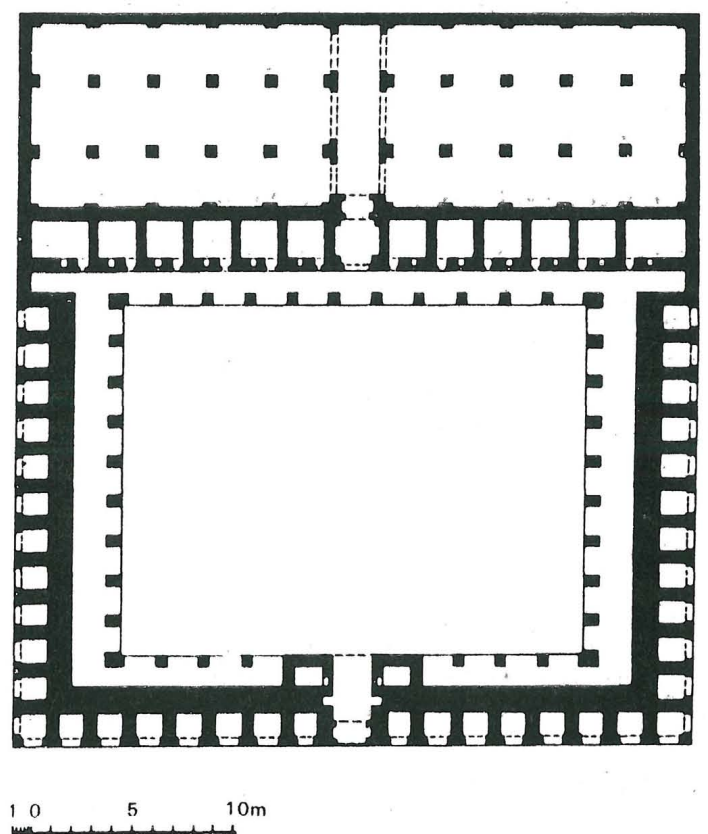

Fig. 3. Caravansar de Eski Malatya.

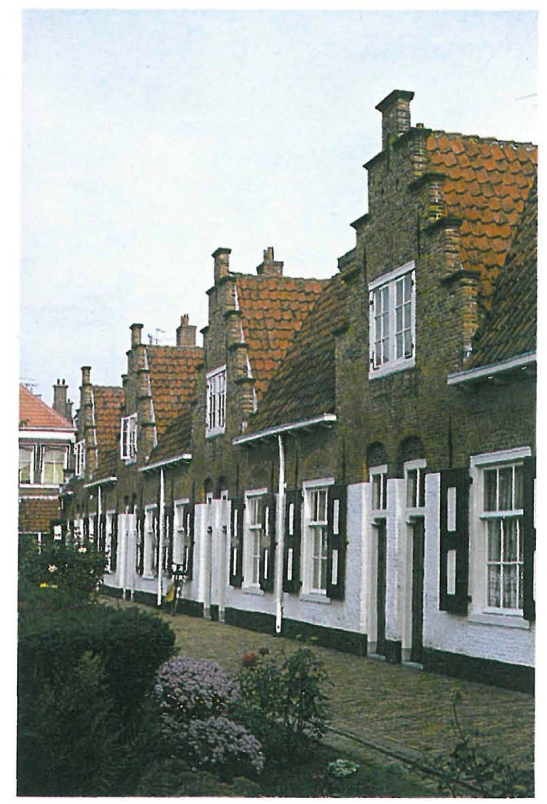

Fig. 4. Beguinaje de Den Haag.
La cartuja de Montalegre (Tiana), construida en los siglos XV y XVII, organiza las celdas alrededor de dos claustros (Fig. 1). Cada celda es una unidad de habitación formada por una casa con solárium, mirador, miniclaustro y huerto. Combina la forma de vida individual, autónoma y solitaria de las casas-celda dedicadas a la vida de oración y trabajo, con el espacio común destinado a la vida religiosa comunitaria. Las celdas configuran su propio ambiente totalmente personalizado por las actividades de los monjes y aisladas del exterior por el muro perimetral.

Un modelo parecido, el "beguinaje" se utiliza aún en los Países Bajos como residencia para la tercera edad (Fig. 4). 


\section{La arquitectura popular}

En otros ejemplos se comprueba la capacidad de adaptación a los cambios de composición familiar o de uso, como en las viviendas populares ibicencas, la casa-torre del Yemen, la casa-patio de Zabid o el poblado Zulú.

La casa rural ibicenca (Fig. 5) se basa en la combinación de cubos de $4 \mathrm{~m}$, que crece progresivamente abrigando un espacio exterior orientado al sur. Se puede modificar continuamente porque no tiene una forma final. Además, como está aislada, se puede modificar a discreción. Puede llegar a tener más de 30 habitaciones.

En el interior del Yemen se ha desarrollado un tipo de edificio básico que se ha adaptado al medio rural y urbano tanto en el altiplano, como en las montañas y la llanura semidesértica (Fig. 6). Se puede construir con materiales diferentes, según las disponibilidades locales, principalmente piedra, ladrillo o barro. Se ha adaptado a los cambios de estructura familiar de los últimos años. Antes el patriarca cabeza de familia vivía en el piso superior y las mujeres, los hijos, los animales, la cocina y el almacén se repartían el resto.
Ahora los descendientes, agrupados en familias monogámicas con pocos hijos, se han repartido por plantas la casa familiar, que forma como una torre de apartamentos. Aún se comparten algunos espacios como la planta baja, que hace de vestíbulo general y almacén, la sala de estar del último piso o "mafraj" espaciosa, iluminada y abierta, con vistas al exterior.

En cambio, en la costa del Mar Rojo, la vivienda está formada por una serie de células de ladrillo, articuladas como un rompecabezas alrededor de un patio interior, configurando recintos cerrados (Fig. 7).

La adaptación a cada familia se realiza ocupando más o menos celdas, o construyendo los espacios libres, o encima de las cubiertas.

Los poblados Zulús del sur de África también se basaban en agrupaciones de celdas (Fig. 8). En este caso eran redondas, de materiales ligeros y se organizaban alrededor de los animales. Las construían las mujeres y el tamaño promedio era de $5 \mathrm{~m}$ de diámetro, aunque variaban según el uso: dormitorio, cocina, almacén de grano, refugio de animales, cuartel de guerreros o palacio real.
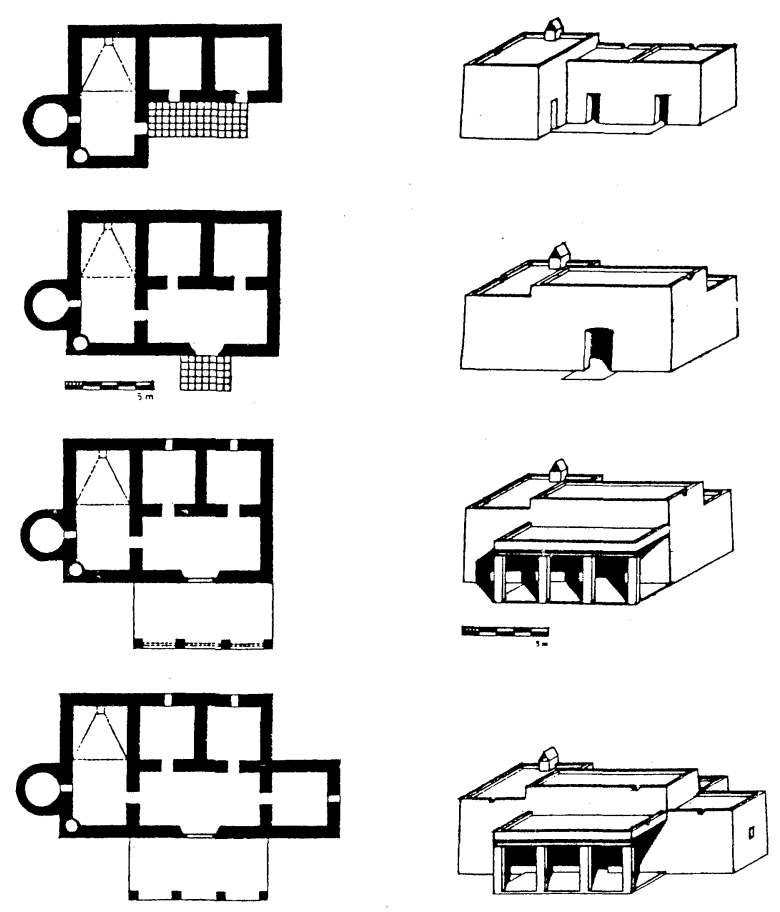
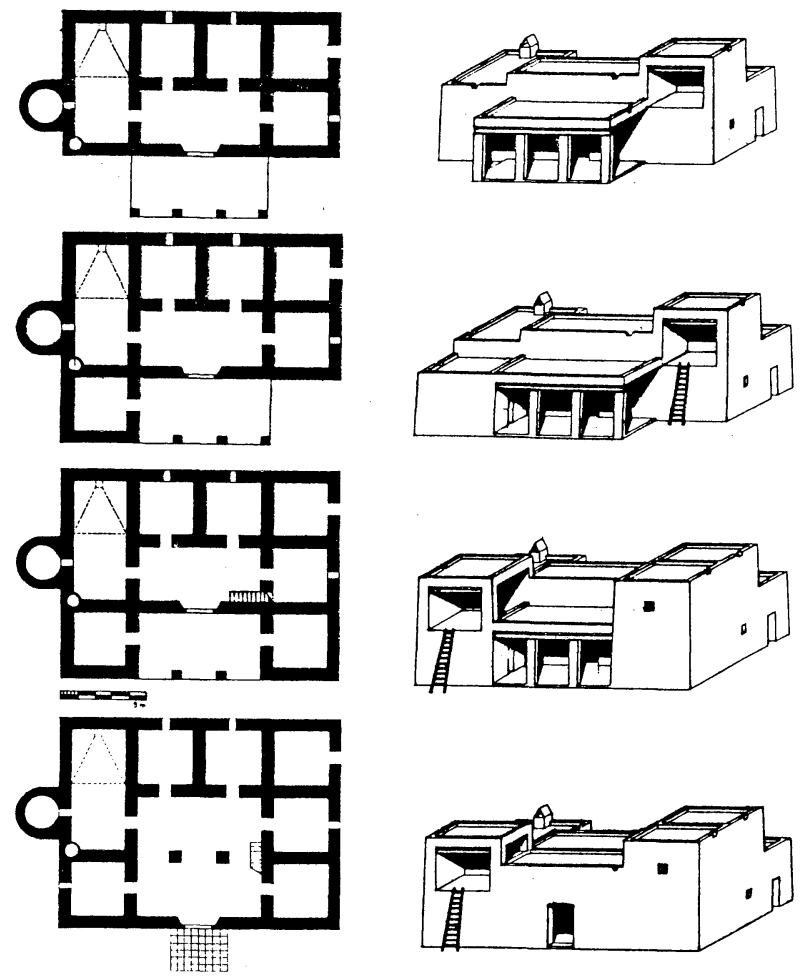

Fig. 5. Casa rural ibicenca. 


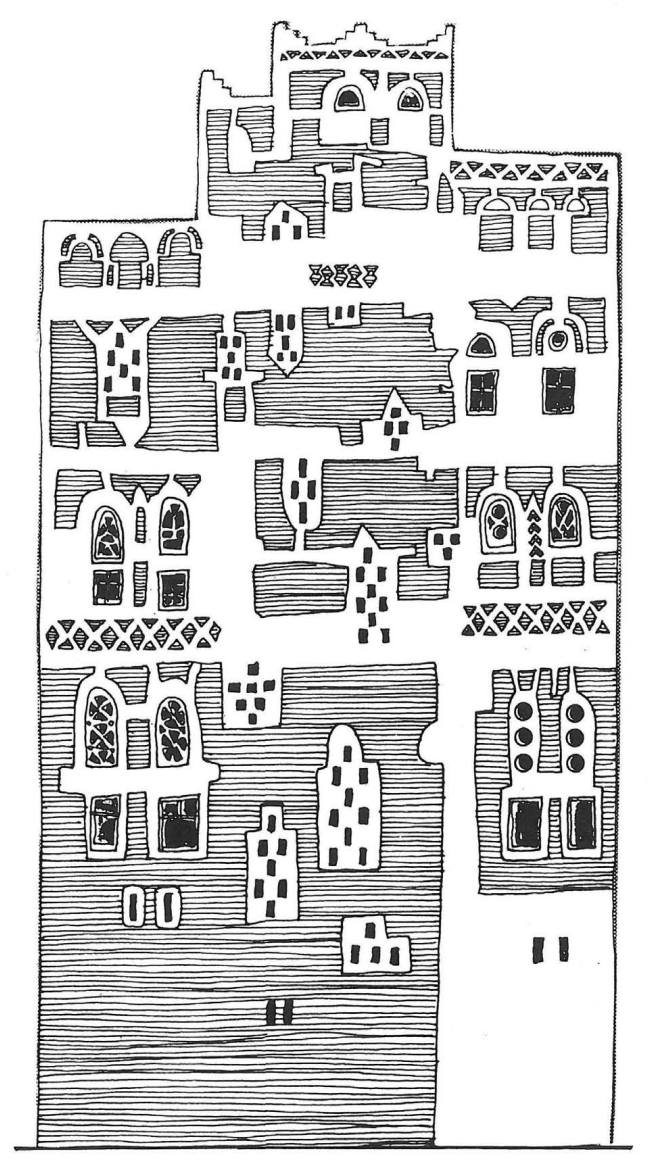

Alzado
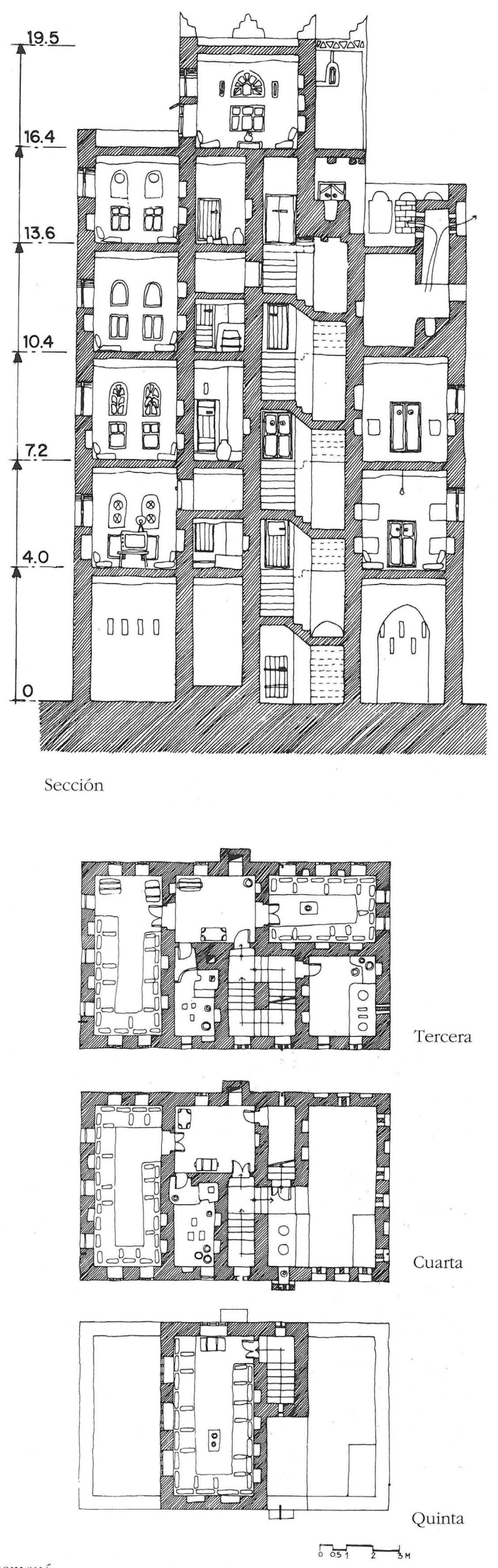

Fig. 6. Casa-torre yemeni. 


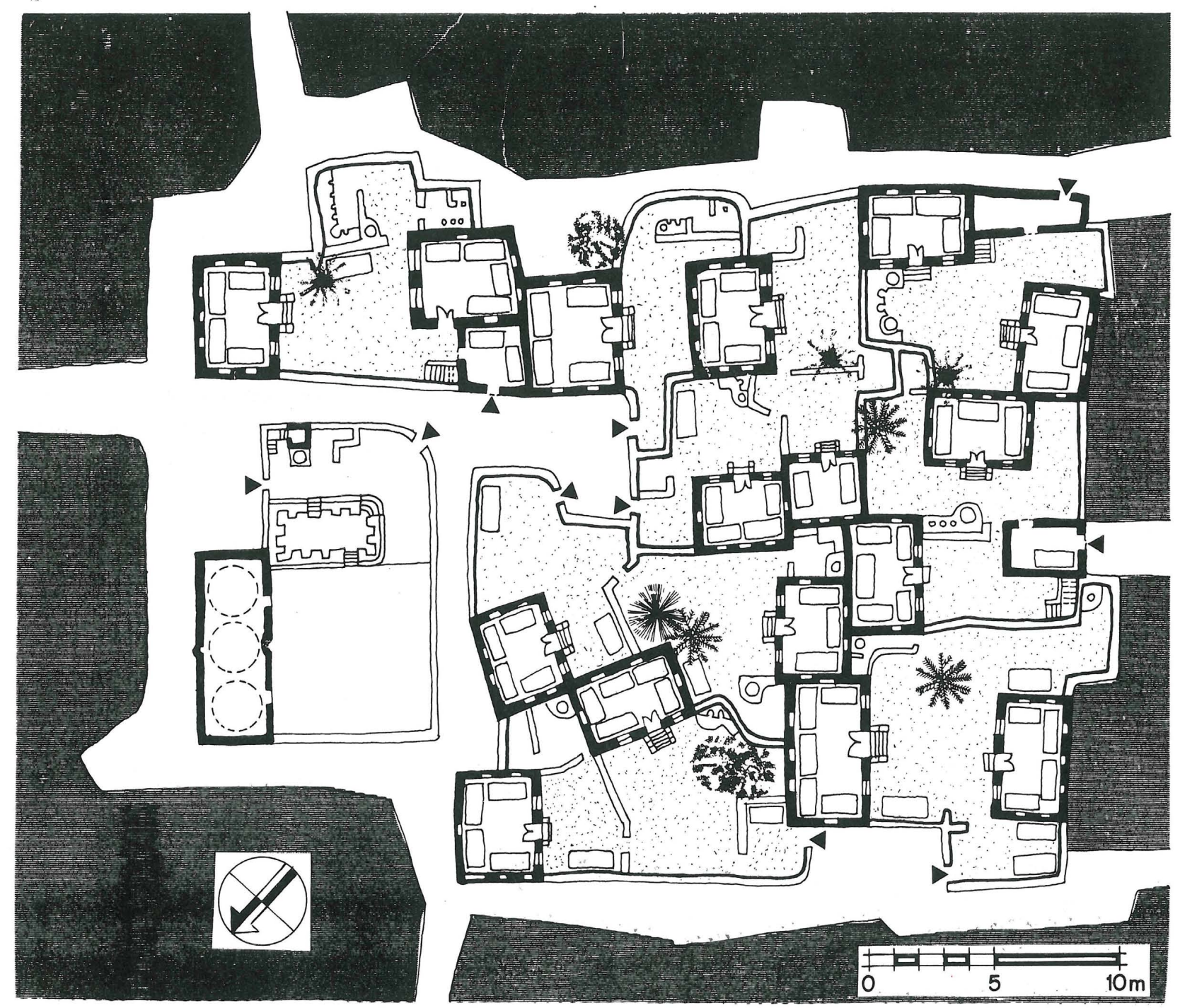

Fig. 7. Casa-patio de Zabid.

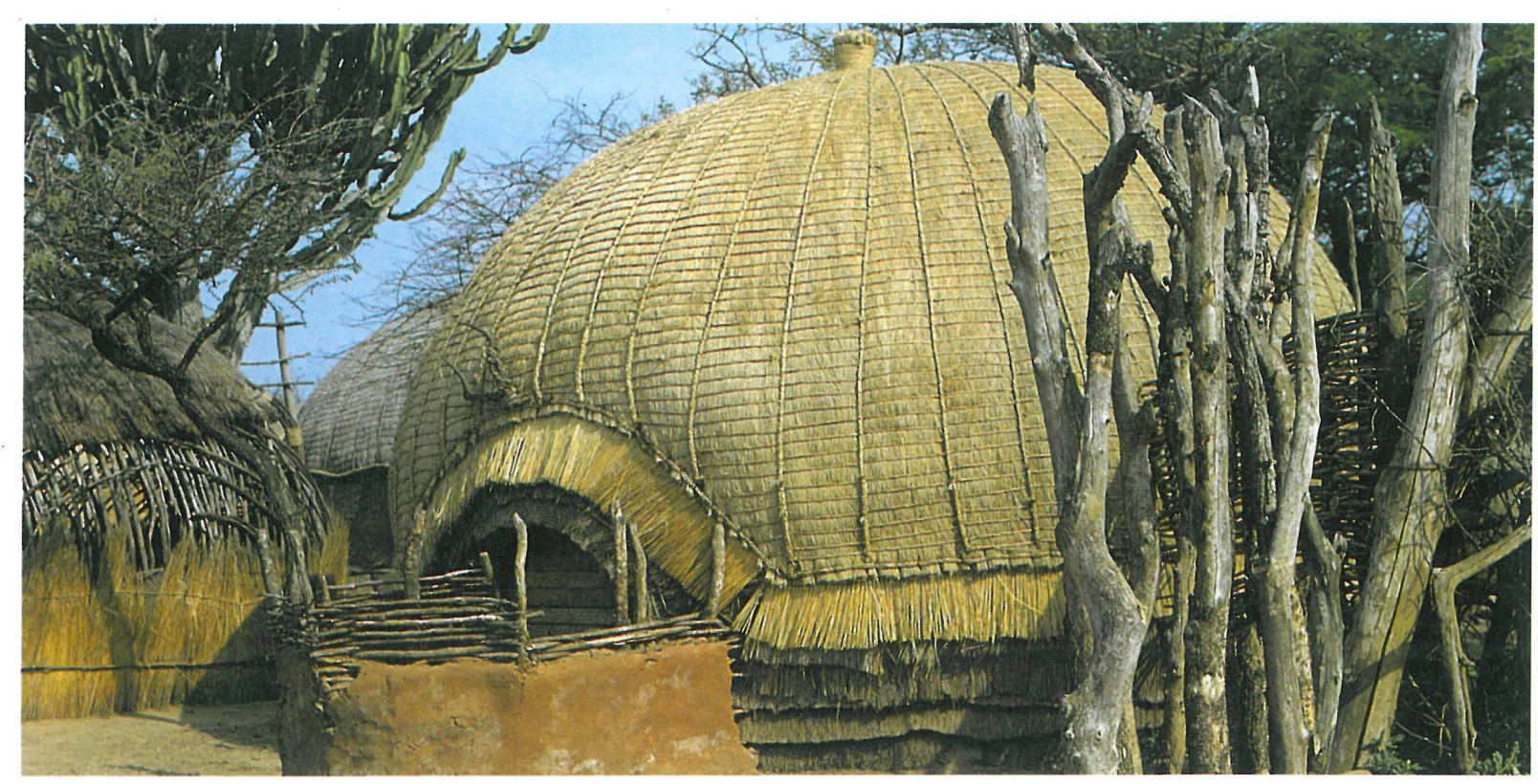

Fig. 8. Poblado Zulú 


\section{El Movimiento Moderno}

La arquitectura culta intervino en la evolución tipológica de la vivienda a partir de la Revolución Industrial, con las propuestas de los utópicos. Más tarde, el Movimiento Moderno defendió la renovación higiénica y funcional. Algunos de sus arquitectos la pusieron en práctica, como es el caso de Le Corbusier. En el Salón de Otoño de París del año 1922, formuló la propuesta de Inmueble-villa, inspirada en el modelo de la cartuja.

Es una superposición de viviendas unifamiliares con terraza-jardín a doble altura (Fig. 9). Comparten un economato en la planta baja. La azotea se acondiciona para jugar al tenis o tomar el sol.

Actualmente hay países que están haciendo un esfuerzo para adaptar las viviendas a la diversidad de la demanda. El caso de Holanda es particularmente interesante. Se trata de un país con una gran tradición en este campo, plasmada por ejemplo en la escuela de Amsterdam de los años veinte, el Betondorp o las experiencias de J. J. Oud.

La cooperativa socialista de viviendas "De Dageraad" (El Alba) encargó un conjunto subvencionado por el Ayuntamiento a los arquitectos M. de Klerk \& P. L. Kramer (Fig. 10). Lo proyectaron con gran cuidado en el tratamiento de las fachadas, que resultaron extraordinarias. La distribución interior de 3 ó 4 habitaciones representó una mejora considerable en las condiciones de vida de la clase trabajadora en aquella época (1919-1922). No faltaron las críticas de los que lo consideraron extravagante e innecesario.

En los años veinte, el Ayuntamiento de Amsterdam convocó un concurso de viviendas prefabricadas para construir en las afueras, a pesar de que la construcción tradicional y conocida era de ladrillo.

Escogieron 10 proyectos que utilizaban 8 sistemas basados en el hormigón vertido en obra, de paneles y bloques. Por esto el barrio fue llamado "Betondorp" (pueblo de hormigón, Fig. 11).

El conjunto de viviendas económicas Kiefhock de J. J. Oud, en Amsterdam, es una disposición en hilera unificada por las franjas horizontales de los bajos, antepechos, ventanas, las superficies curvas, los colores y el revoco blanco que en Holanda carece de tradición (Fig. 12). El interior dividido en 2 plantas de $7,5 \times 4,1$ (o sea, $61,50 \mathrm{~m}^{2}$ en total) se reparte entre la planta baja con recibidor, sala de estar, cocina y wc, y la planta piso con 3 dormitorios. Fue presentado al Congreso Internacional de Arquitectura Moderna (CIAM) como vivienda mínima.

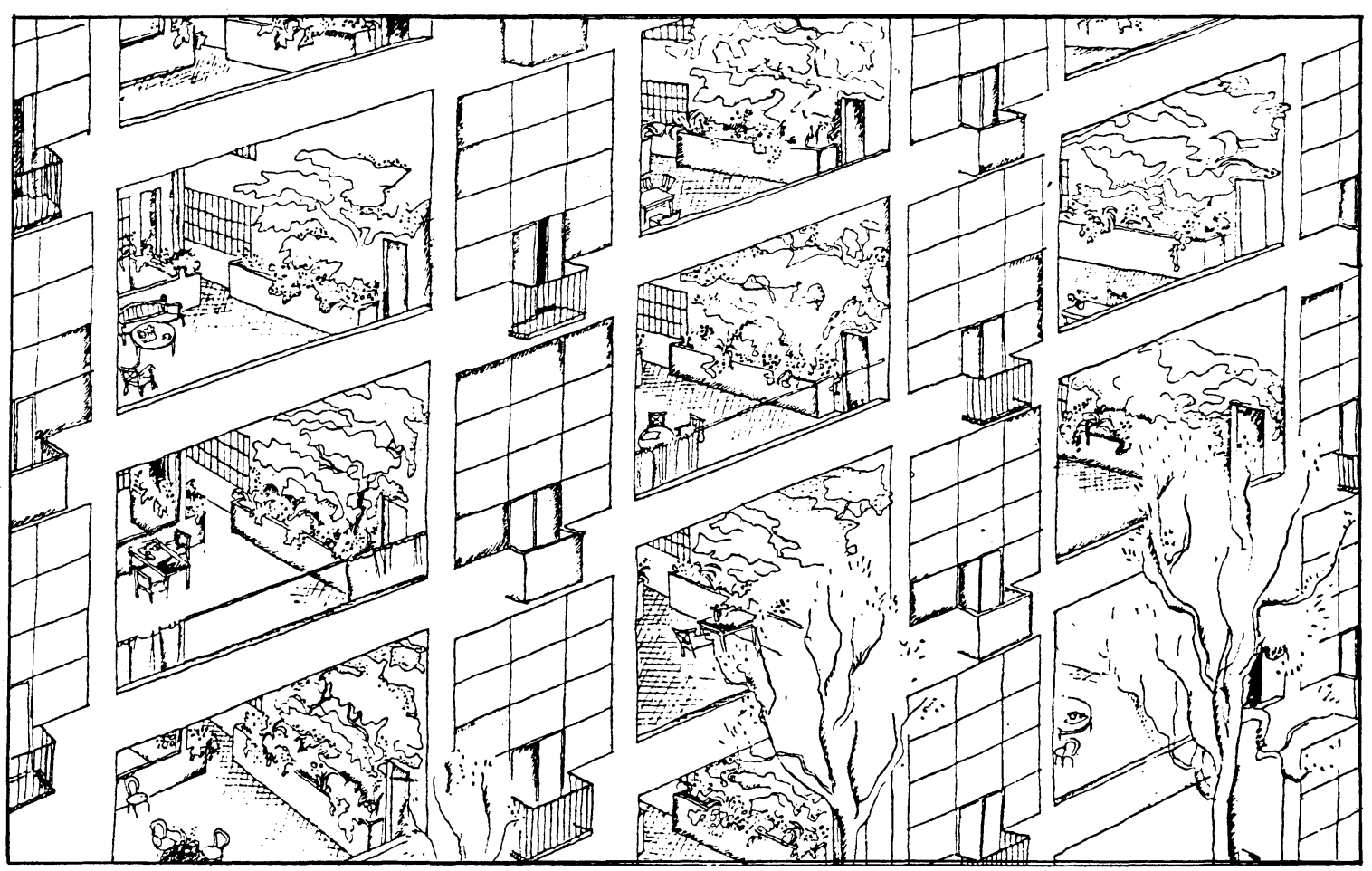

Fig. 9. El "inmueble-villa", edificio alveolar de Le Corbusier, 1992 
Informes de la Construcción, Vol. 46, n. ${ }^{\circ}$ 434, noviembre/diciembre 1994

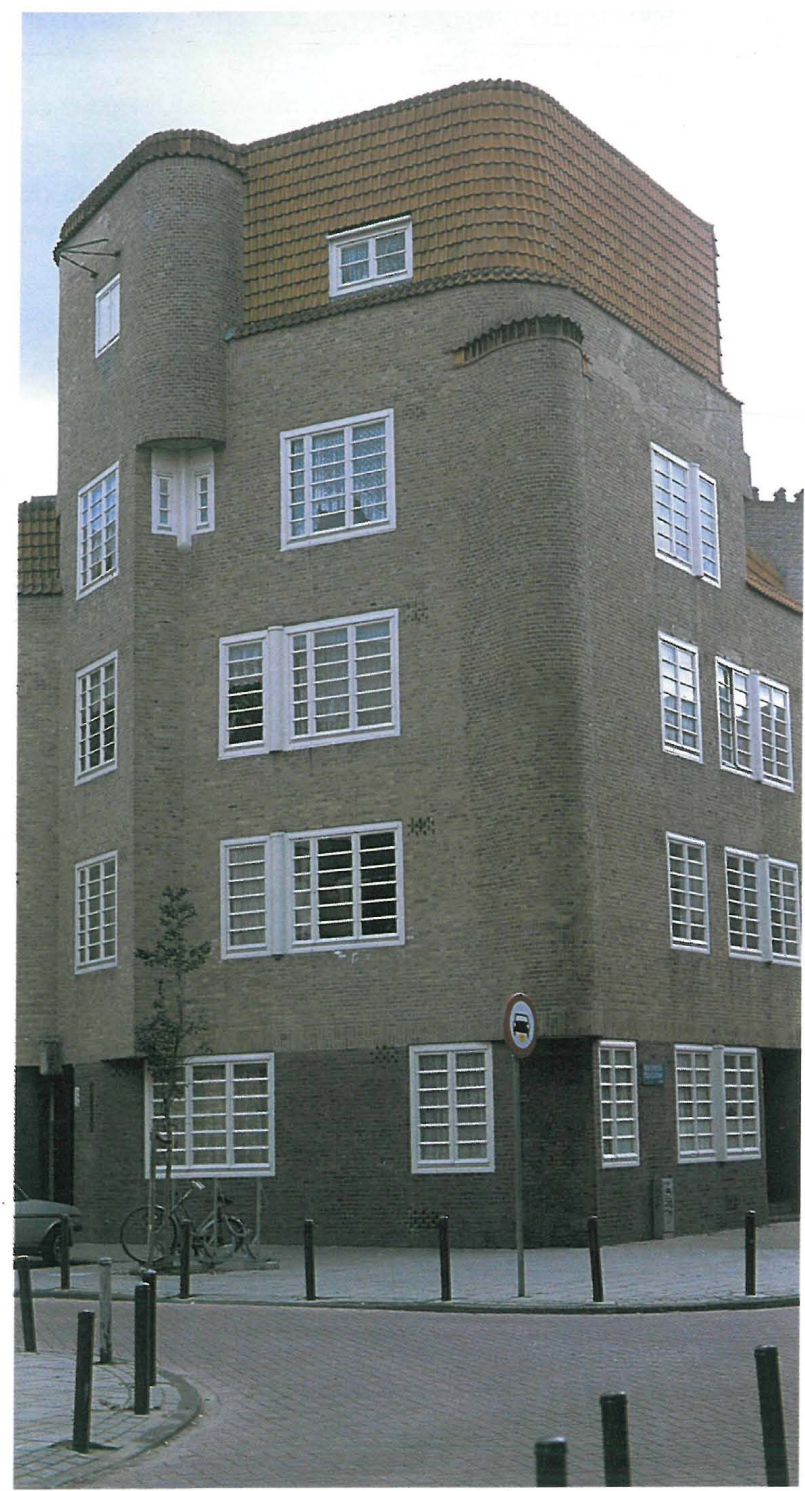

Fig. 10. M. de Klerk \& P. L. Kramer, Amsterdam.

\section{Ejemplos contemporáneos. Holanda}

Actualmente la política de viviendas de la Administración holandesa ha asumido los cambios demográficos y la modificación del programa familiar. Se ha concretado en algunas realizaciones como el edificio de viviendas para estudiantes, trabajadores, solteros, parejas jóvenes y viejos del grupo Mecanoo en Kruisplein, Rotterdam (Fig. 13). Es una respuesta explícita a los problemas de adaptación que presentaron las viviendas de postguerra, destinadas a familias convencionales. En Holanda, ya hace tiempo que el número de habitantes por vivienda disminuye, a la vez que la población envejece. Es necesario investigar nuevos tipos más adaptables a situaciones diferentes.

El edificio de viviendas "De Zwaan" del Atelier Pro en Voorburg, cerca de Den Haag, incluye apartamentos de varios tipos para poder adaptarse a usuarios diferentes, incluyendo los de poder adquisitivo moderado (Fig. 14). Resultan especialmente adecuadas para parejas, solteros o grupos formados por estudiantes, hermanos, madre con hijos y personas mayores. Se utiliza el modelo de servicios compartidos con habitaciones independientes.

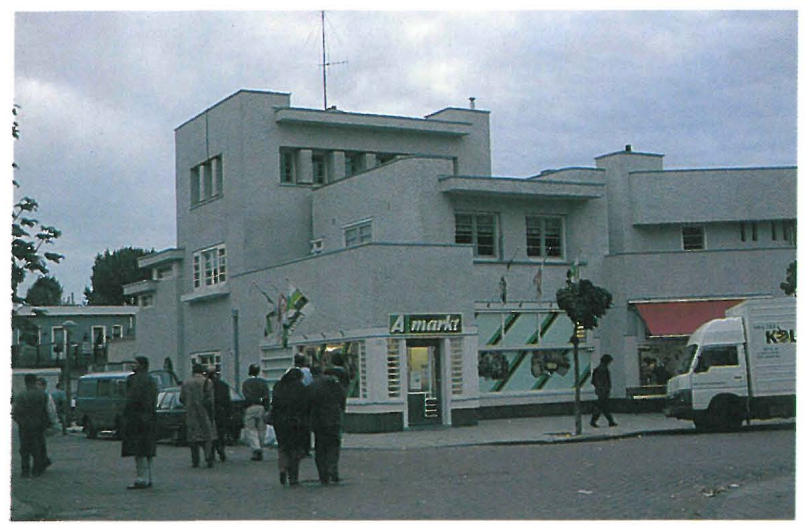

Fig. 11. Betondorp (barrio de bormigón), Amsterdam.

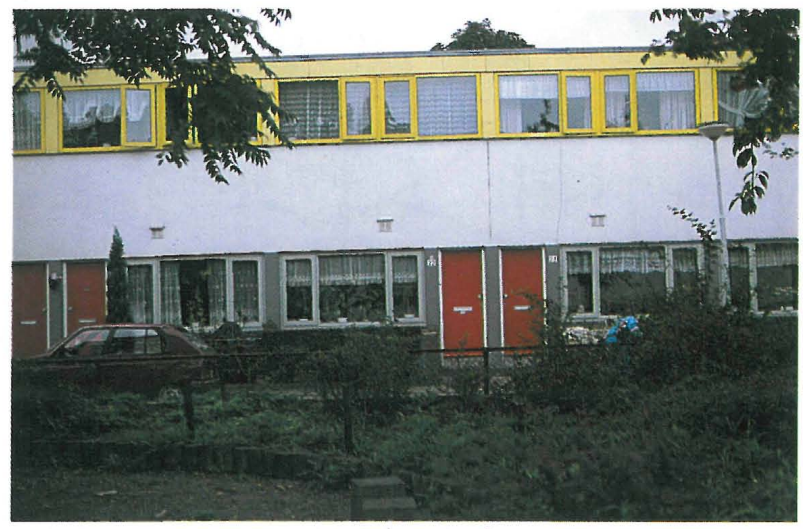

Fig. 12. Grupo Kiefhock, Rotterdam.

(c) Consejo Superior de Investigaciones Científicas 


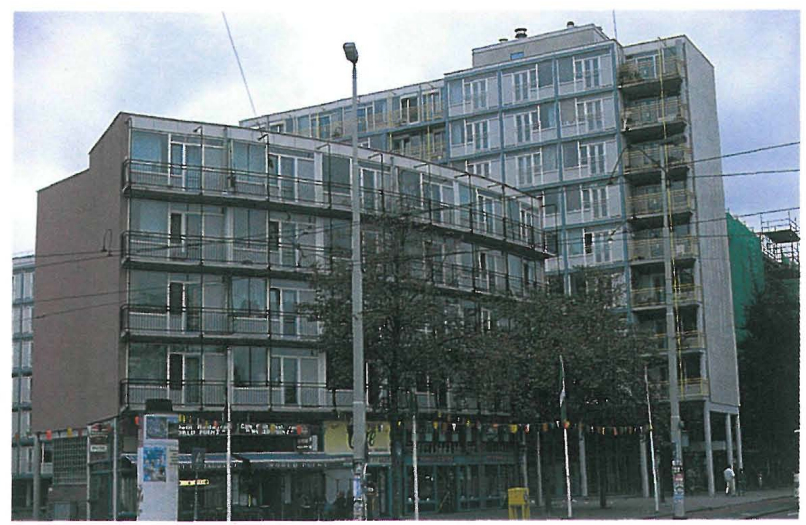

Fig. 13. Bloque de viviendas, Kruisplein, Rotterdam
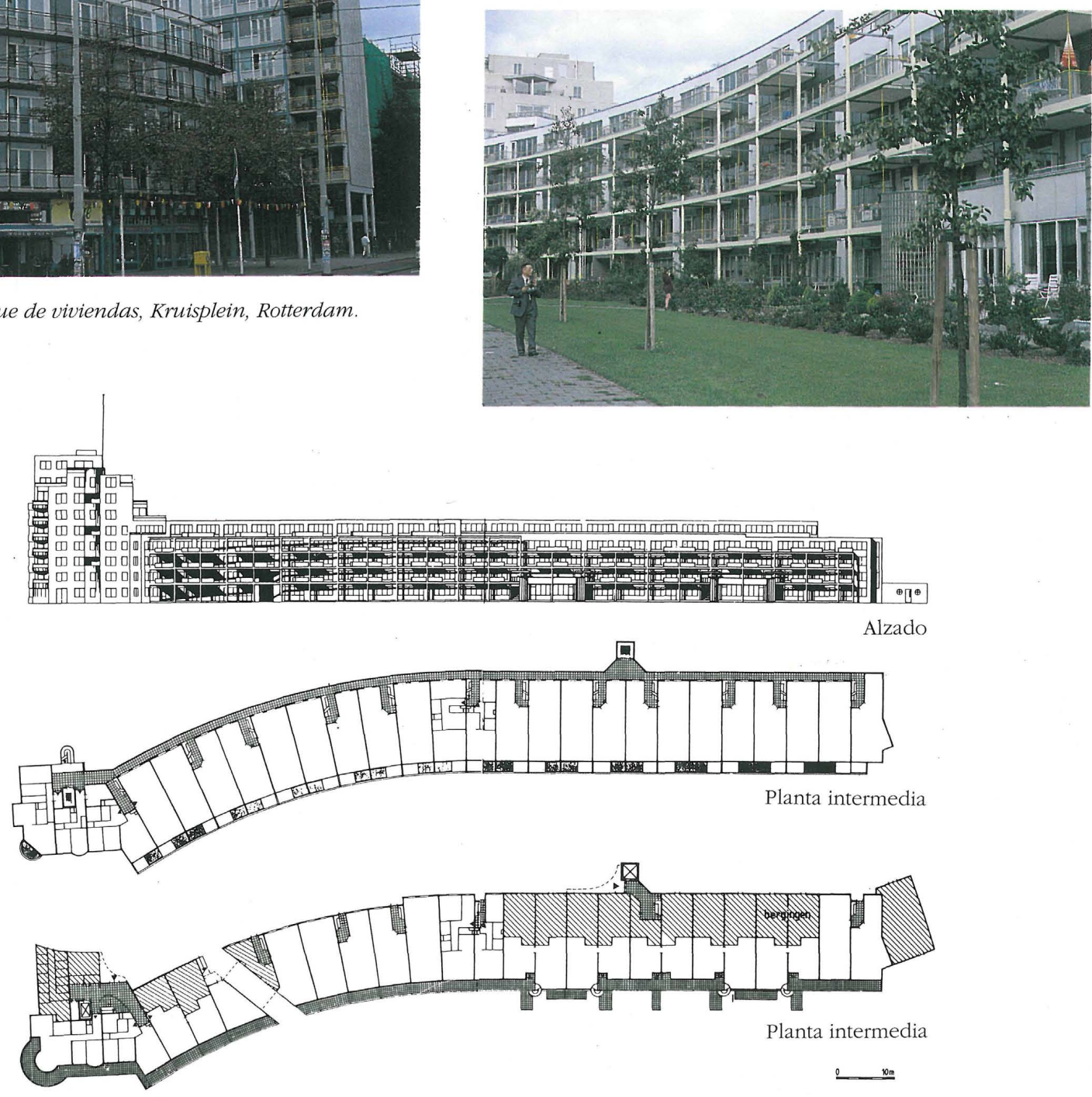

Fig. 14. Edificio de viviendas "De Zwaan" (el Cisne), Voorburg.

La cooperativa socialista de viviendas "De Dageraad" ha reutilizado los almacenes portuarios "Entrepotdok" de Amsterdam para construir 400 viviendas sociales, oficinas, tiendas, estudios, almacenes y aparcamientos (Fig. 15). La intervención consistió en colocar las viviendas en las 3 últimas plantas, vaciando el interior del bloque para crear una serie de patios centrales y poder circular, acceder, ventilar e iluminar. Las viviendas han resultado superiores a lo habitual $\left(35 \mathrm{~m}^{2}\right.$ para la sala de estar y de 11 a $15 \mathrm{~m}^{2}$ para los dormitorios) porque era mucho más económico respetar los murós originales que derribarlos y volverlos a construir. La adaptación de las viviendas a las características singula- res de cada edificio ha permitido generar 18 tipos diferentes de 2 a 6 dormitorios, estudios y unidades para grupos no familiares.

La fundación "De Fantaisie" organiza concursos de proyectos experimentales y cede parcelas proporcionadas por el Ayuntamiento de Almere a los ganadores, con la condición de que las construyan y habiten (Fig. 16). Entre las experiencias realizadas destaca la de Holvast \& Van Woerden. Es una vivienda adaptable a cualquier tipo de terreno, con estructura tubular para andamios apoyada sobre flotadores cilíndricos de acero. El edificio es un contenedor reducido y compacto muy bien aislado y fácil 


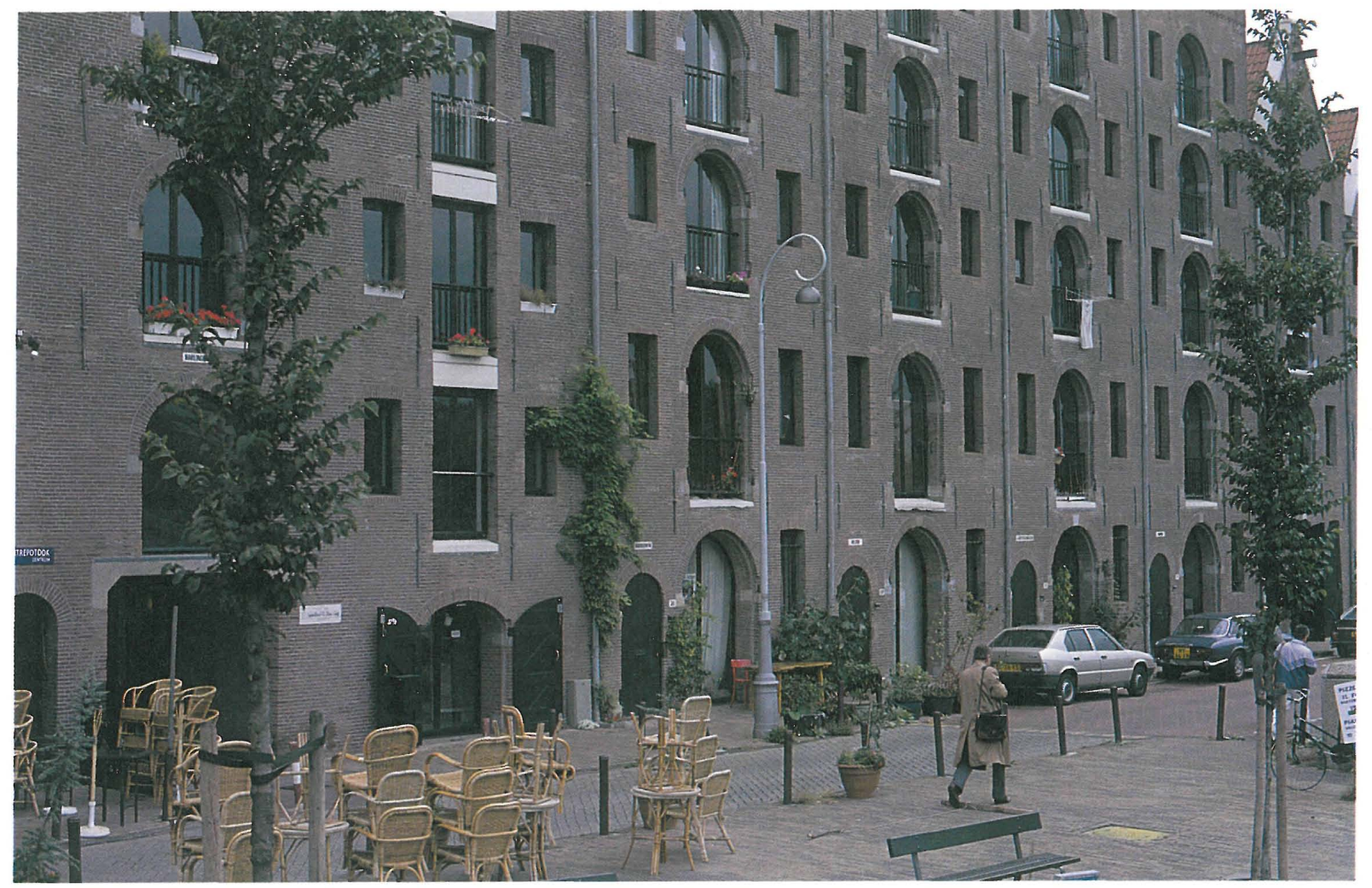

Fig. 15. "Entrepotdok", Amsterdam

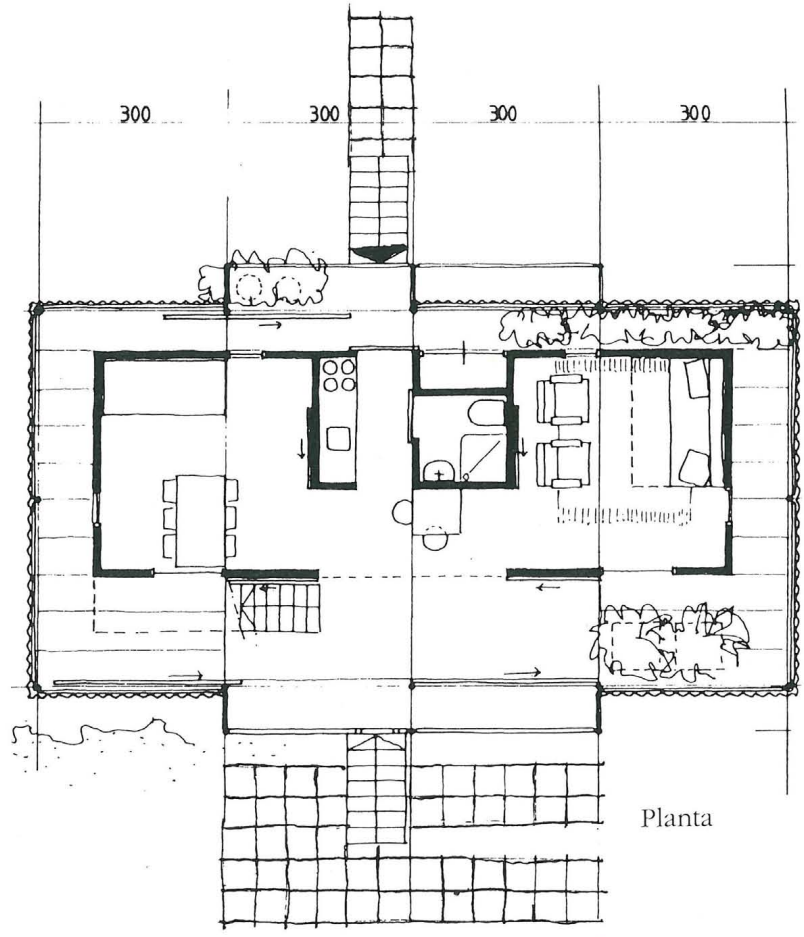

Fig. 16. Vivienda unifamiliar, Holvast $\&$ Van Woerden, Almere.
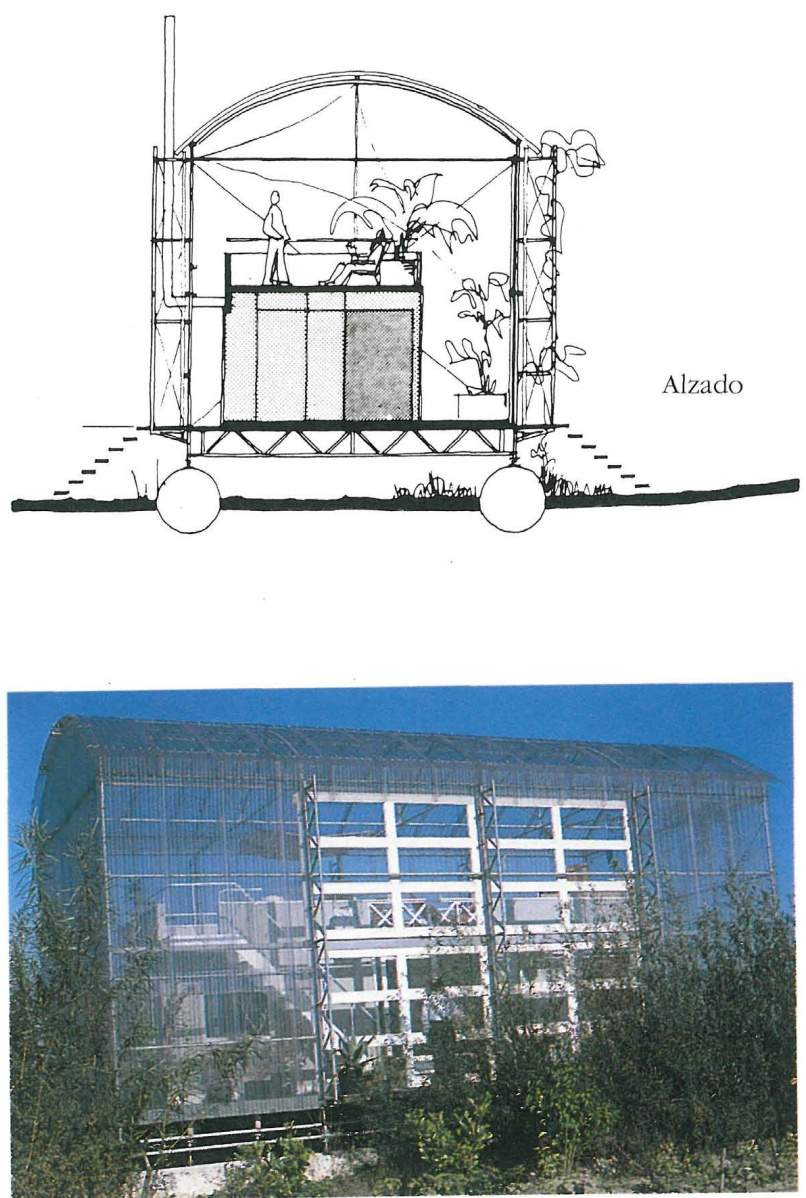

(c) Consejo Superior de Investigaciones Científicas 

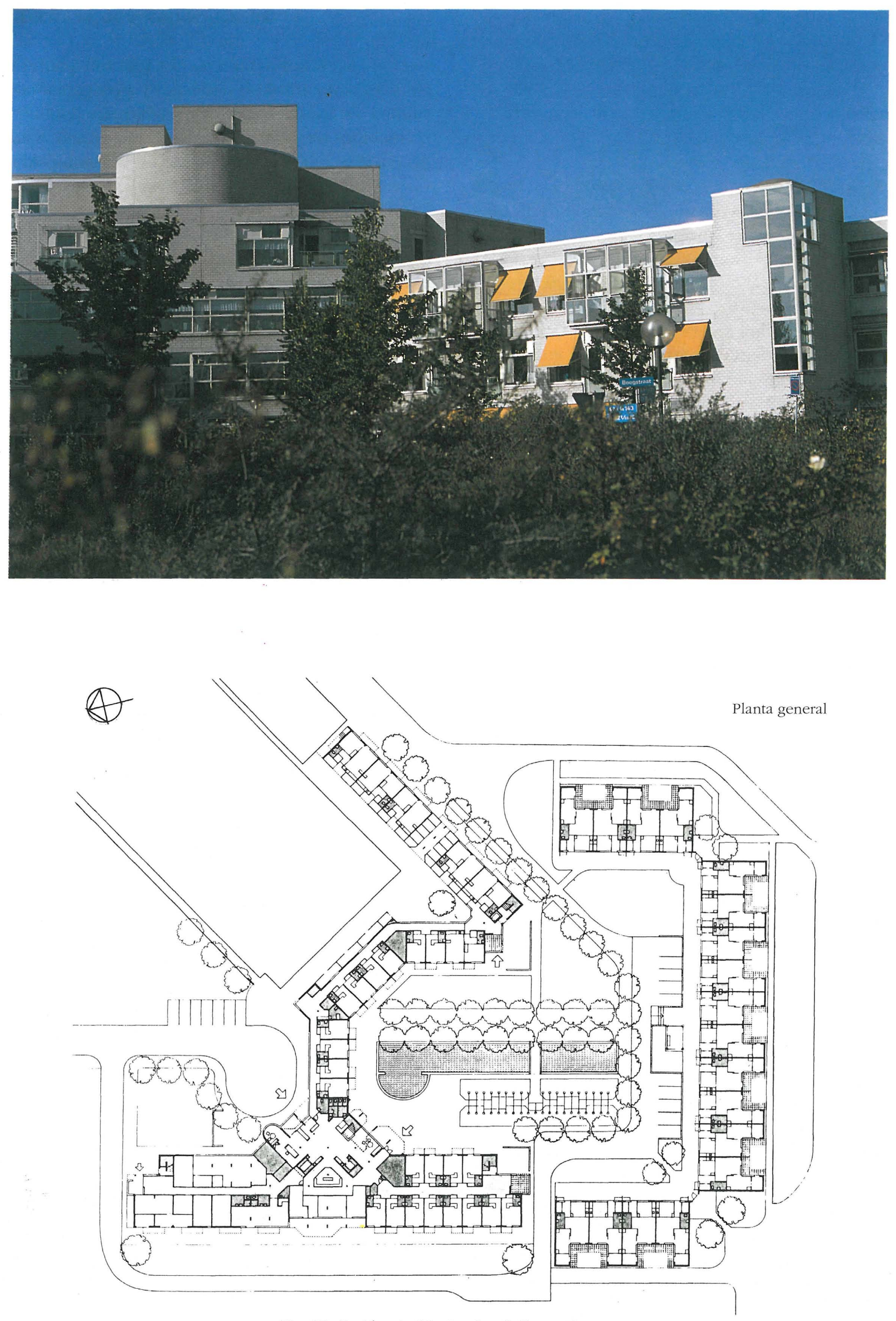

Fig. 17. Residencia "De Overloop" Almere Haven. 
de acondicionar, recubierto por una envolvente de placa ondulada translúcida. El espacio intermedio protege al núcleo central, pudiendo utilizarse cuando la temperatura lo permite. Con el sol de invierno la temperatura interior puede llegar a $18^{\circ} \mathrm{C}$ y en verano se puede ventilar.

El conjunto residencial para ancianos "De Overloop" en Almere Haven de Herman Hertzberger incluye 84 unidades individuales, 8 dobles, la enfermería, 20 apartamentos de 2 personas independientes y 18 viviendas con 3 habitaciones (Fig. 17). Se caracteriza porque gradúa la complejidad y autonomía de las viviendas desde los apartamentos independientes de los extremos del edificio hasta las habitaciones asistidas próximas al núcleo central, que actúa como centro de relación.

\section{Francia}

En Francia también se realizan algunos experimentos. París vivió en los años veinte la transformación de las buhardillas en estudios o talleres para artistas sin recursos. En los ochenta se han reutilizado antiguos almacenes industriales y lavaderos que han quedado atrapados en el casco urbano. Es la versión organizada de la transformación, muchas veces ilegal y espontánea, de los edificios industriales de New York, que han producido los "loft", un nuevo tipo de vivienda consolidado (Fig. 18).

En Nîmes, con iniciativa y promoción del Ayuntamiento, el arquitecto Jean Nouvel ha realizado el

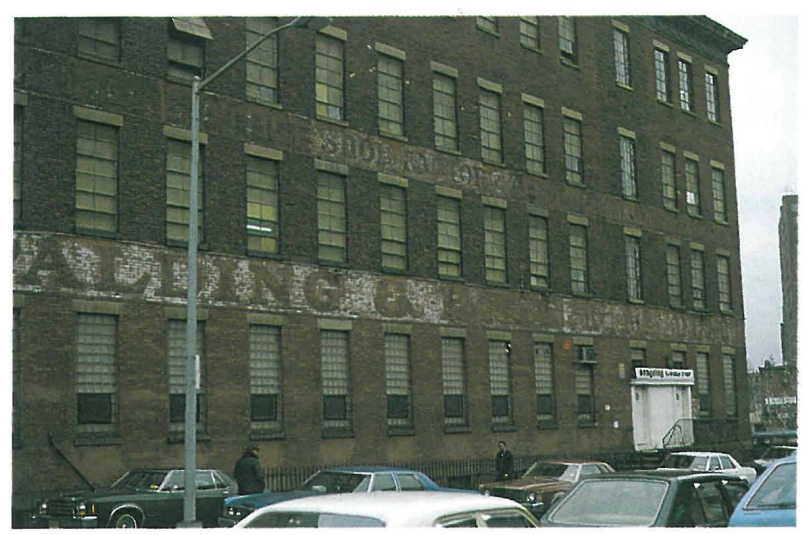

Fig. 18. Fábrica reutilizada para viviendas ilegales. Brooklun. conjunto "Nemausus" que une el sistema constructivo con la forma y el tipo funcional (Fig. 19). Es un caso especialmente interesante porque, años después de la construcción, se ha estudiado el comportamiento y las opiniones de los usuarios para valorar el grado de satisfacción. La respuesta social a las propuestas innovadoras del edificio han sido muy variadas dependiendo de las características culturales, económicas y sociales. Hay usuarios que se han integrado al edificio, otros lo han transformado para adaptarlo a sus necesidades, y también los hay que lo han abandonado.

En Lyon, los arquitectos Jourda \& Perraudin se han autoconstruido en 2 meses su vivienda con materiales ligeros (Fig. 20). Se trata de una caja de acero y cristal, protegida por una cubierta textil muy grande. De esta manera se definen 2 niveles de protección, como en el caso de Holvast \& Van Woerden de Almere. La organización del espacio interior queda muy poco condicionada por la estructura envolvente, de manera que se puede modificar.

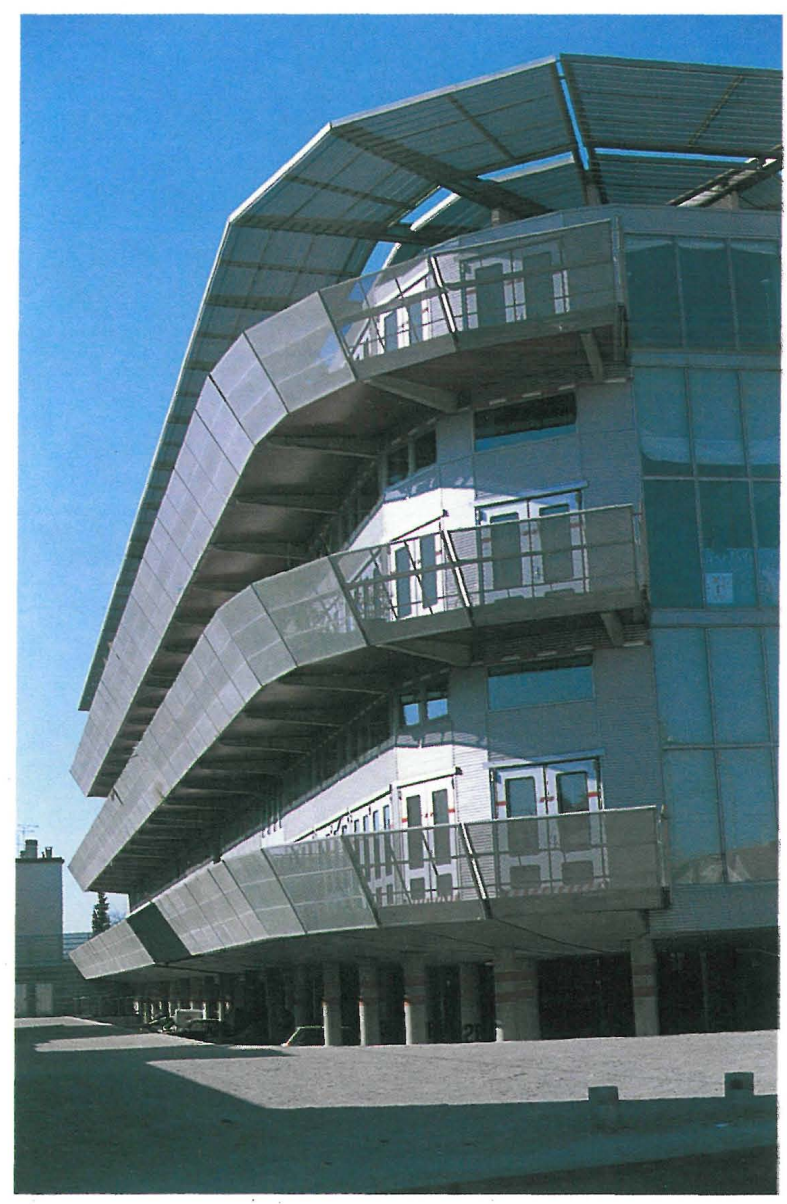

Fig. 19. Bloque "Nemausus". Nimes. 


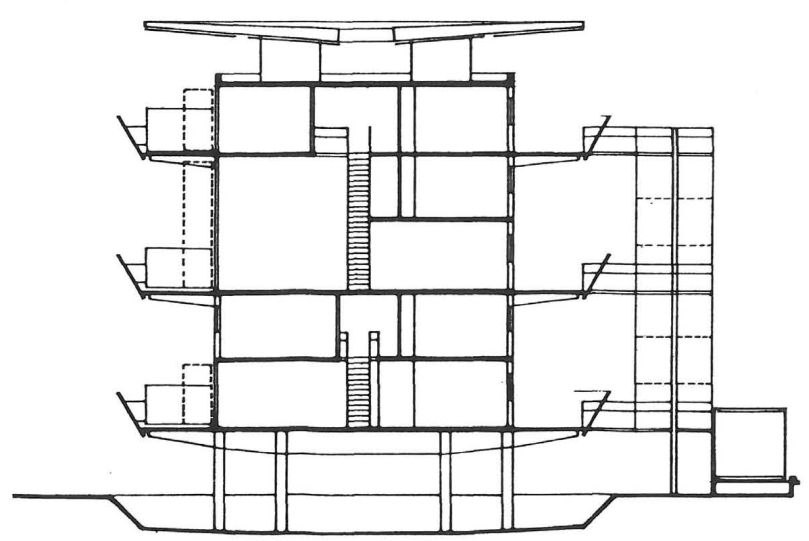

Seccion
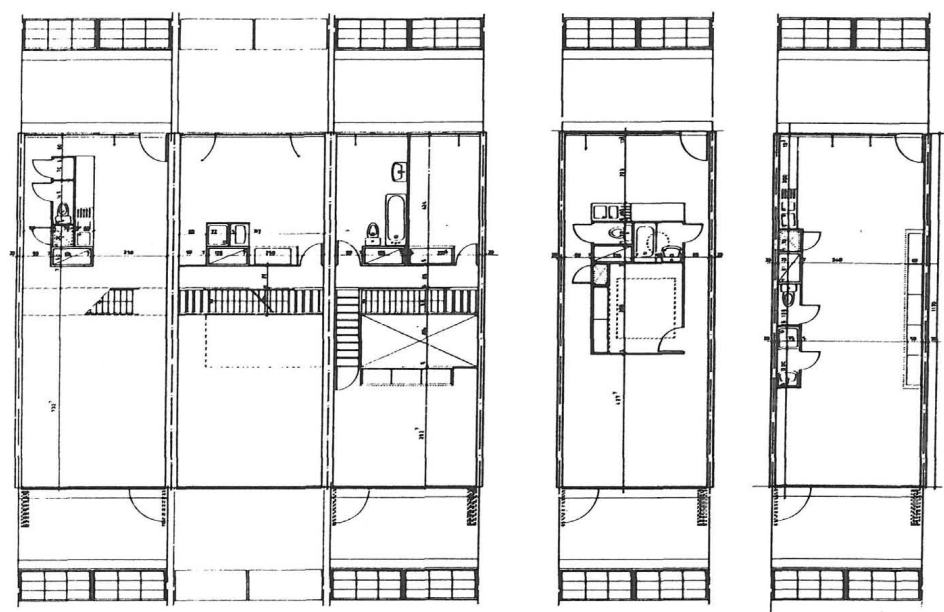

Planta.

Fig. 19. Bloque "Nemansus". Nimes,

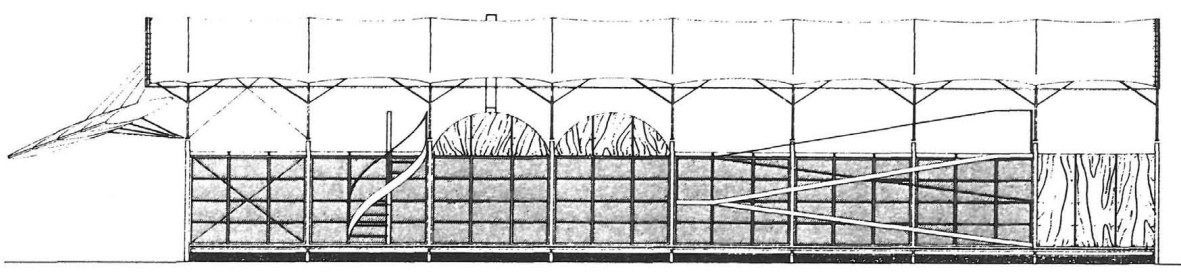

Alzado

Perspectiva

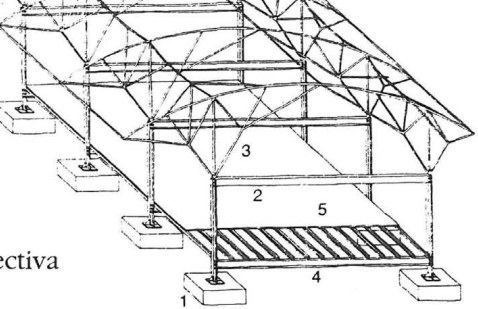

1. Cimentación. 2. Pórticos de acerero galvanizadlo. 3. Estructura de cubierta. 4. Viguetas. 5. Tablero de madera.

Planta

1. Vestíbulo. 2. Estar. 3. Cocina. 4. Dormitorio. 5. Baño. 6. Oficio. 7. WC. 8. Terraza. 9. Jardín.

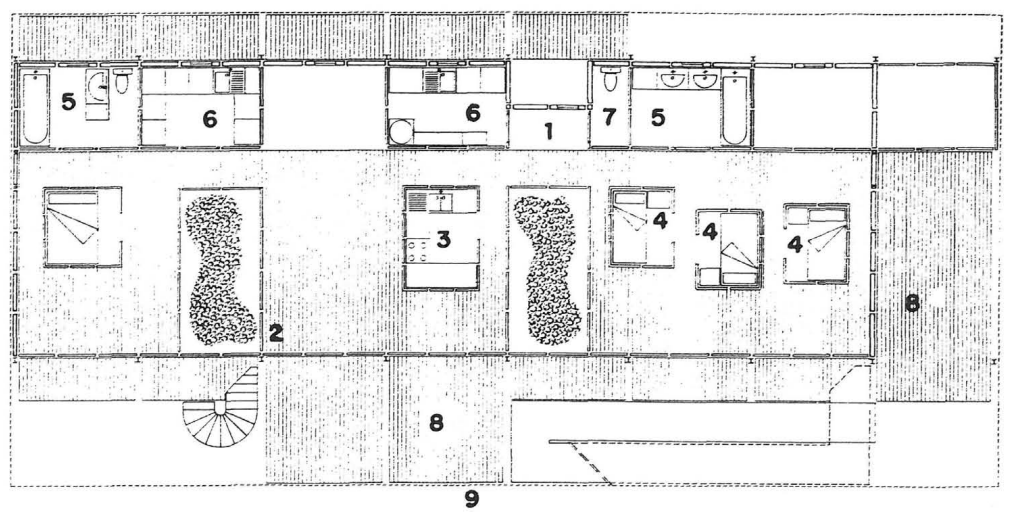

Fig. 20. Vivienda unifamiliar, Jourda \& Perraudin, V'aise, Lyon. 


\section{Reino Unido}

En Inglaterra, a pesar de que el mercado de la vivienda continúa dominado por las viviendas en hilera entre medianeras tradicionales, algunos arquitectos en la línea "high-tech" han apli- cado materiales industriales actuales a la resolución de la vivienda. Destaca el caso de Michael \& Patty Hopkins que han desarrollado su vivienda con estructura ligera y cerramientos de acero y cristal, en seco sin materiales tradicionales (Fig. 21).

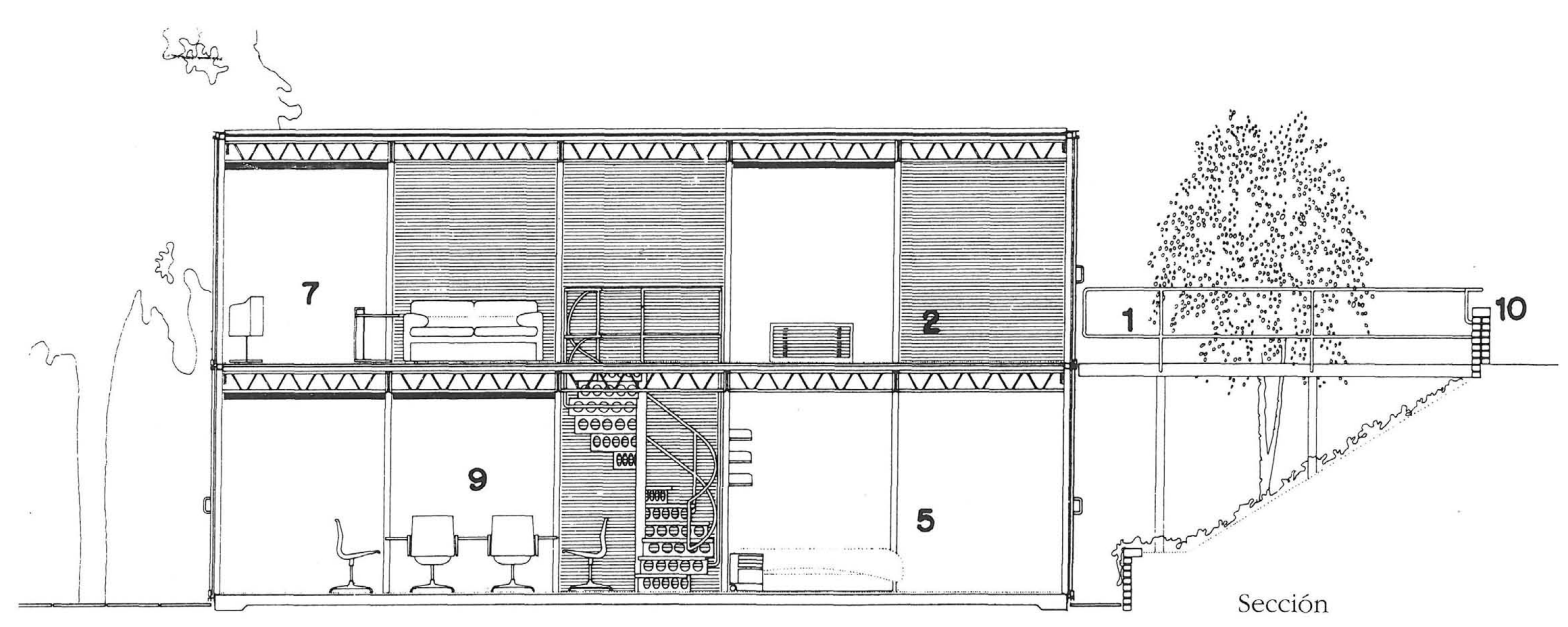

1. Pasarela de acceso. 2. Vestíbulo. 3. Estudio. 4. Ducha. 5. Dormitorio. 6. Vestidor. 7. Estar. 8. Cocina. 9. Comedor. 10. Calle. 11. Jardín.

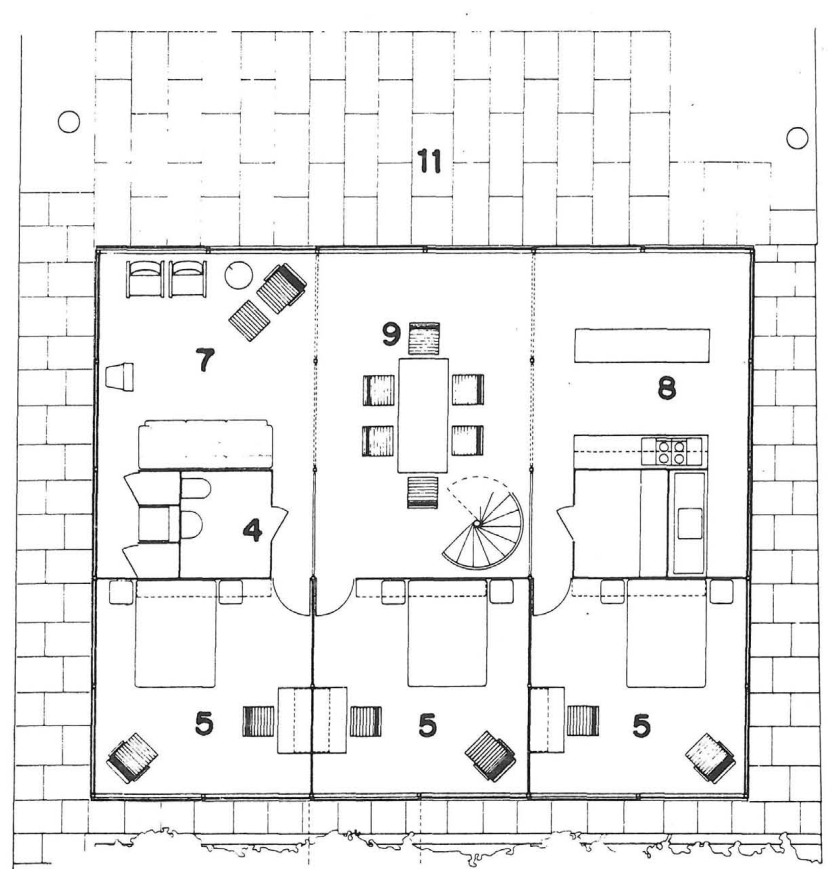

Planta baja.

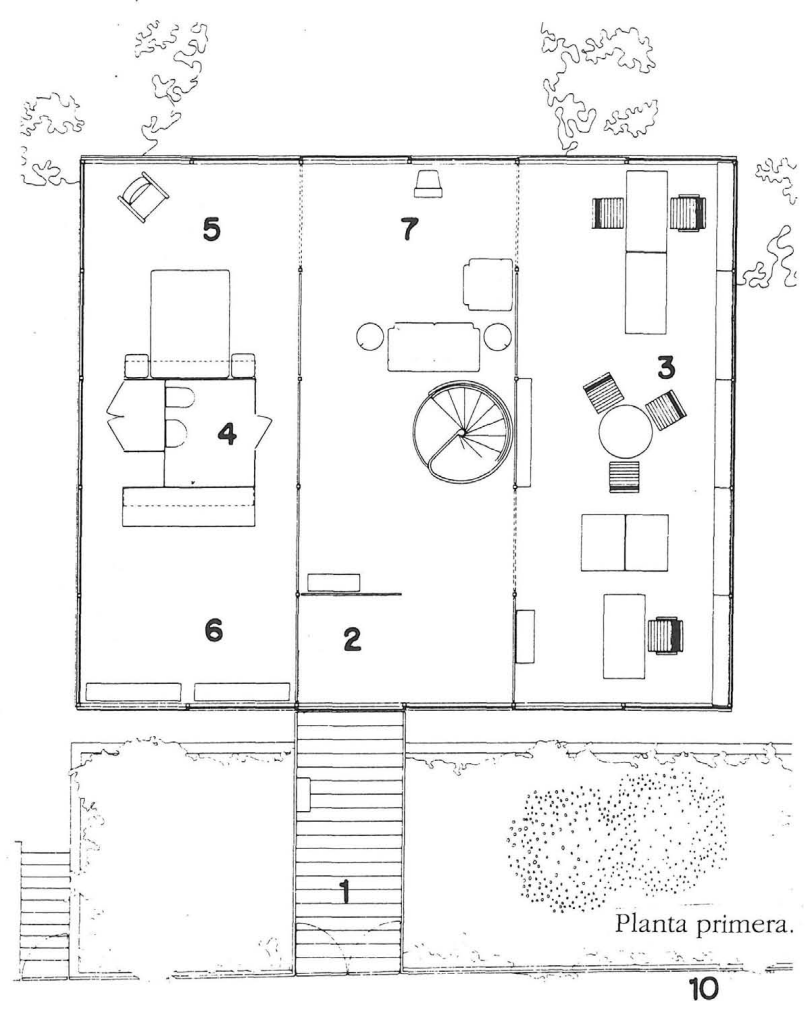

Fig. 21. Vivienda unifamiliar, Michael \& Patty Hopkins, Londres. 


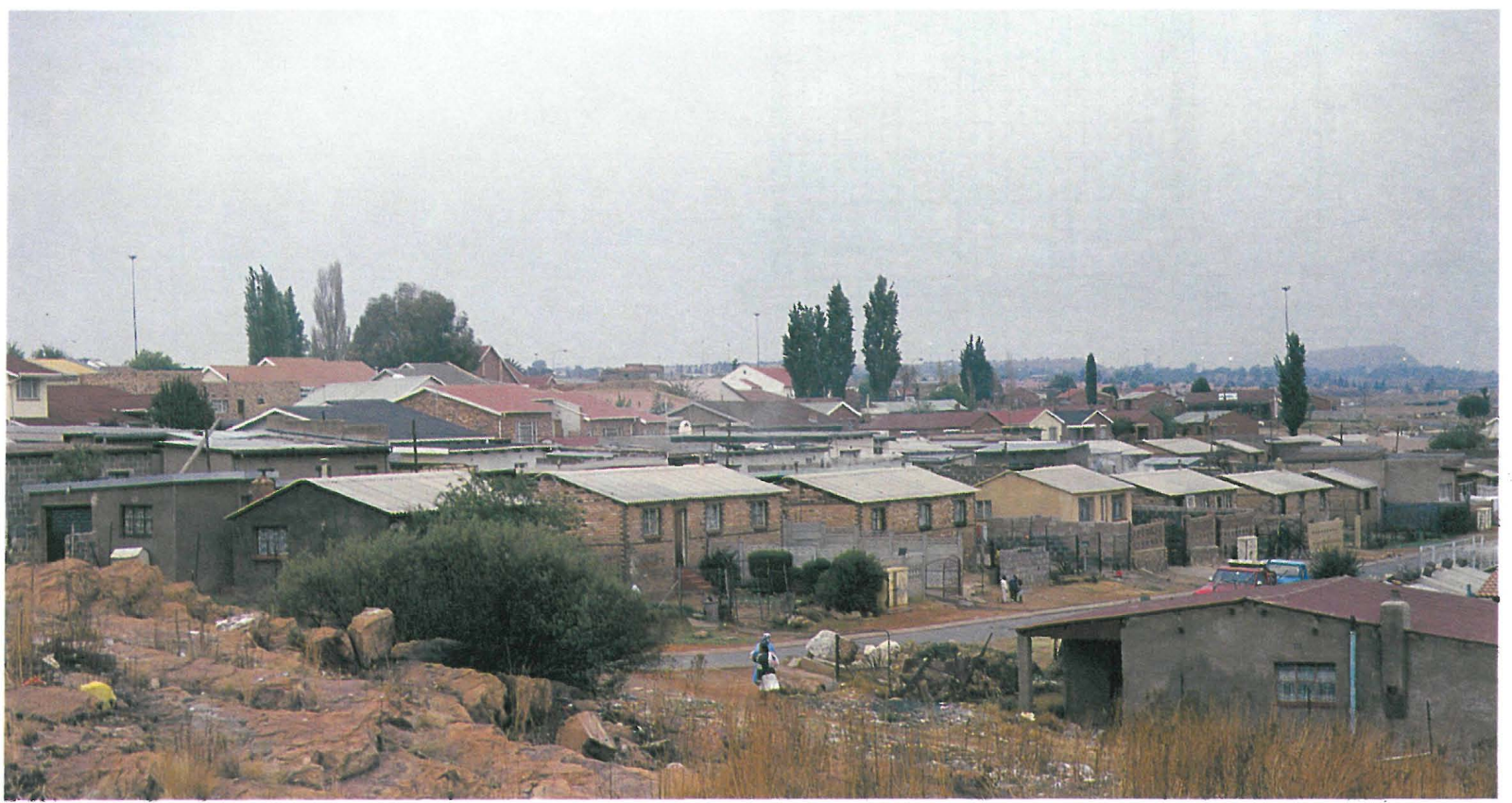

Fig. 22. Sou'eto, Johannesburg.

La autoconstrucción es otra fuente de experimentación relativa a la adaptación de la vivienda a las características específicas de grupos diversos. Es el caso de los emigrantes de las zonas rurales a las capitales en los países en desarrollo, como por ejemplo Ankara o Lima, y también de las concentraciones de negros en los países con segregación racial, como Soweto en Johannesburg (Fig. 22).

\section{La situación actual en España}

En España las experiencias realizadas son muy escasas e insuficientes. La inercia del sector de la construcción es muy conservadora. El mercado repite lo que se ha venido haciendo hasta ahora y la Administración tampoco quiere asumir riesgos. De todas maneras, los precios inaccesibles y la falta de variedad invitan a proponer alternativas de cara al futuro.

\section{Los locales habitables}

En esta línea, se presenta el proyecto de "locales habitables" para la construcción de un tipo de vivienda que, a partir de unos mínimos asequibles, no solamente pueda adaptar su distribución y pres- taciones a las posibilidades económicas, sino que también se pueda modificar con facilidad.

Para adaptarse al usuario, tanto a su poder adquisitivo como a su composición familiar, programa y actividades, se plantea la vivienda como un contenedor rectangular vacío muy bien aislado de $4 \mathrm{~m}$ de ancho, $12 \mathrm{~m}$ de profundidad y 5 de altura, equipado con una puerta a doble altura y una gran ventana sobre los lados menores, que son las fachadas, y un armario-patinejo de instalaciones y ventilación en el centro (Fig. 23). La rebaja que se puede obtener con relación al precio de construcción actual es de un 40 por ciento. A partir de aquí, se puede completar más o menos subdividiendo el espacio y equipándolo con plataformas intermedias, escaleras interiores, armarios, tabiques, acabados, mobiliario, plantas e instalaciones. Se pueden realizar soluciones convencionales (Fig. 24) y soluciones singulares para situaciones particulares diferentes (Fig. 25).

La adaptación a emplazamientos diferentes, a partir de la unidad básica, se consigue con las agrupaciones y los elementos intermedios, como por ejemplo los accesos, porches y terrazas. Se pueden organizar conjuntos urbanos, rurales, de alta y baja densidad, en hilera, manzana, aislados, en bloque o en torre (Fig. 26). 


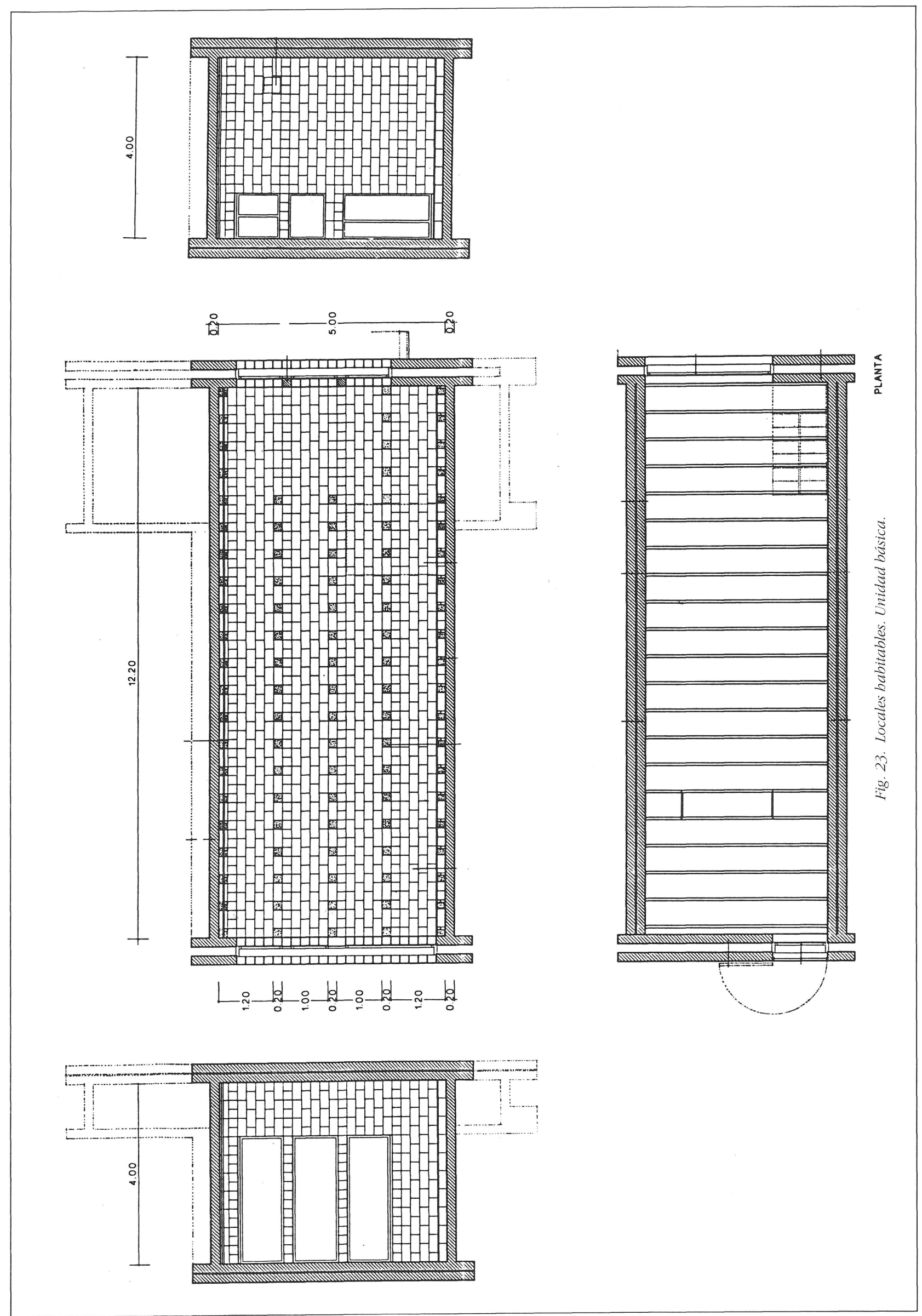



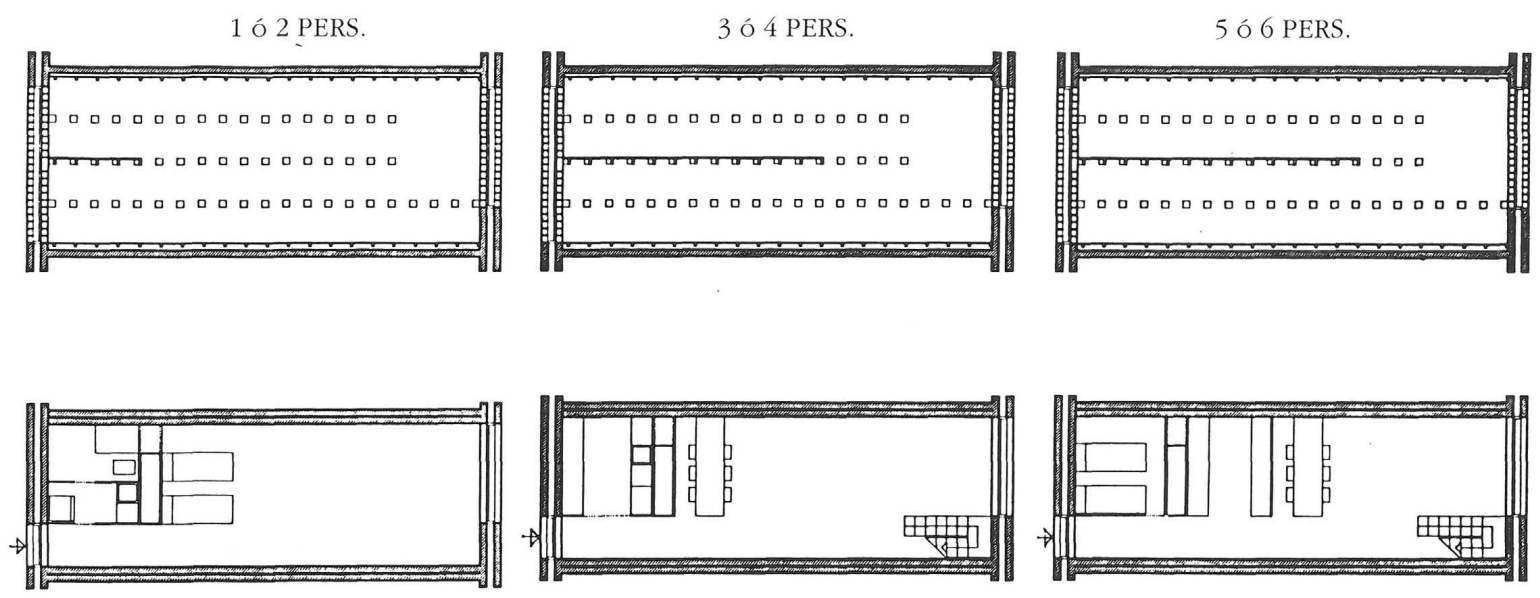

PLANTAS

PLANTAS

PLANTAS
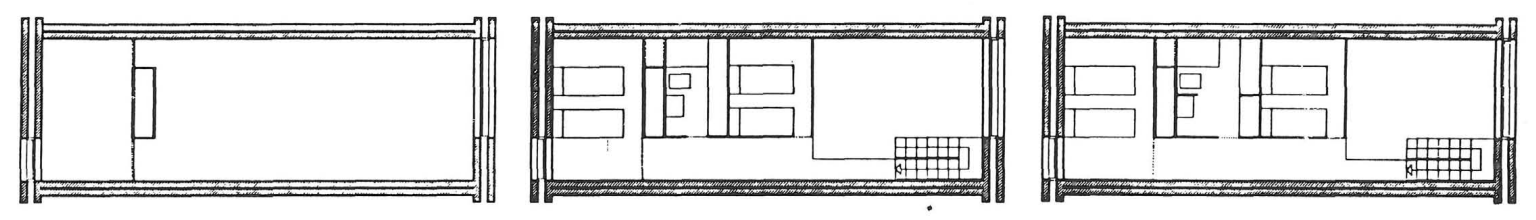

Fig. 24. Agrupaciones de locales adaptados a la vivienda convencional.

En base a este prototipo, se han construido unas cuantas viviendas unifamiliares aisladas o en conjuntos de ciudad jardín, como la casa Riera, en Alella, publicada en el número 406 de esta revista y las viviendas económicas realizadas con bloque de hormigón del número 344-345.

También son posibles las agrupaciones urbanas que desarrollan la unidad básica adaptándose a diferentes puntos de la ciudad, como por ejemplo al nuevo polígono de Canaletes, Cerdanyola (Fig. 26). Se trata de dos bloques lineales de 14 y 28 viviendas, resultado de superponer en uno de ellos dos filas de 14 contenedores. El acceso se realiza directamente a cada vivienda desde galerías exteriores que unifican la yuxtaposición de módulos en sentido horizontal. Los muros son de hormigón armado vertido en obra o de bloque de mortero visto de $40 \mathrm{~cm}$ de espesor y situados cada $4 \mathrm{~m}$. Los forjados son prelosas completadas en obra y separadas $5 \mathrm{~m}$ en altura. El usuario, si quiere, puede colocar una o más plataformas intermedias de viguetas de madera o chapa plegada. Se alojan en hornacinas previstas en los muros o se apoyan sobre ménsulas ancladas con tacos a la pared.
El pavimento se forma con una o dos capas de machihembrado de madera, que puede o no incluir aislante acústico para disminuir el impacto y la transmisión. Las fachadas pueden ser de bloque de mortero o paneles prefabricados de hormigón u otro material. Si se desea compartimentar el espacio interior, pueden utilizarse puertas correderas de madera sobre guías Klein.

La carpintería exterior es de aluminio y doble cristal. Incorpora una capa de aislante en los elementos opacos frente a los antepechos y se completa con postigos interiores aislados y blindados. Al cerrarlos, restituyen totalmente la continuidad del muro exterior a efectos de aislamiento y protección. Las instalaciones se enchufan al armario-patinejo central. Los recorridos horizontales transcurren por el interior del cielo raso o por debajo del pavimento flotante de los forjados superiores e inferiores. El trazado de la acometida hasta los puntos de consumo se realiza en dirección vertical.

Con este sistema constructivo se obtiene una parte fija básica mínima siempre igual para todos, que es el contenedor, y otra opcional, en seco y autoconstruible por fases para los cerramientos interiores, las instalaciones y acabados y el acondicionamiento interior. 


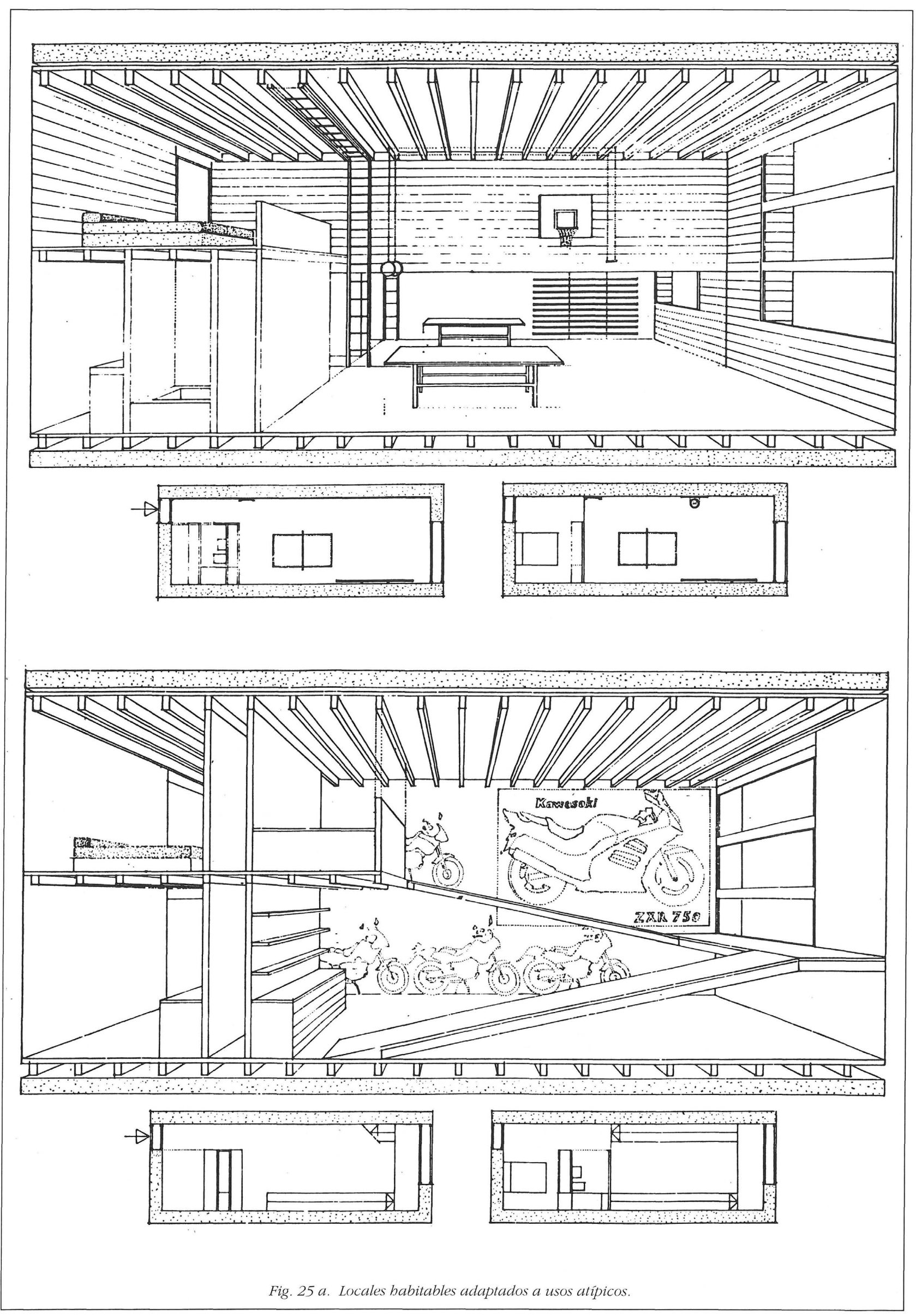



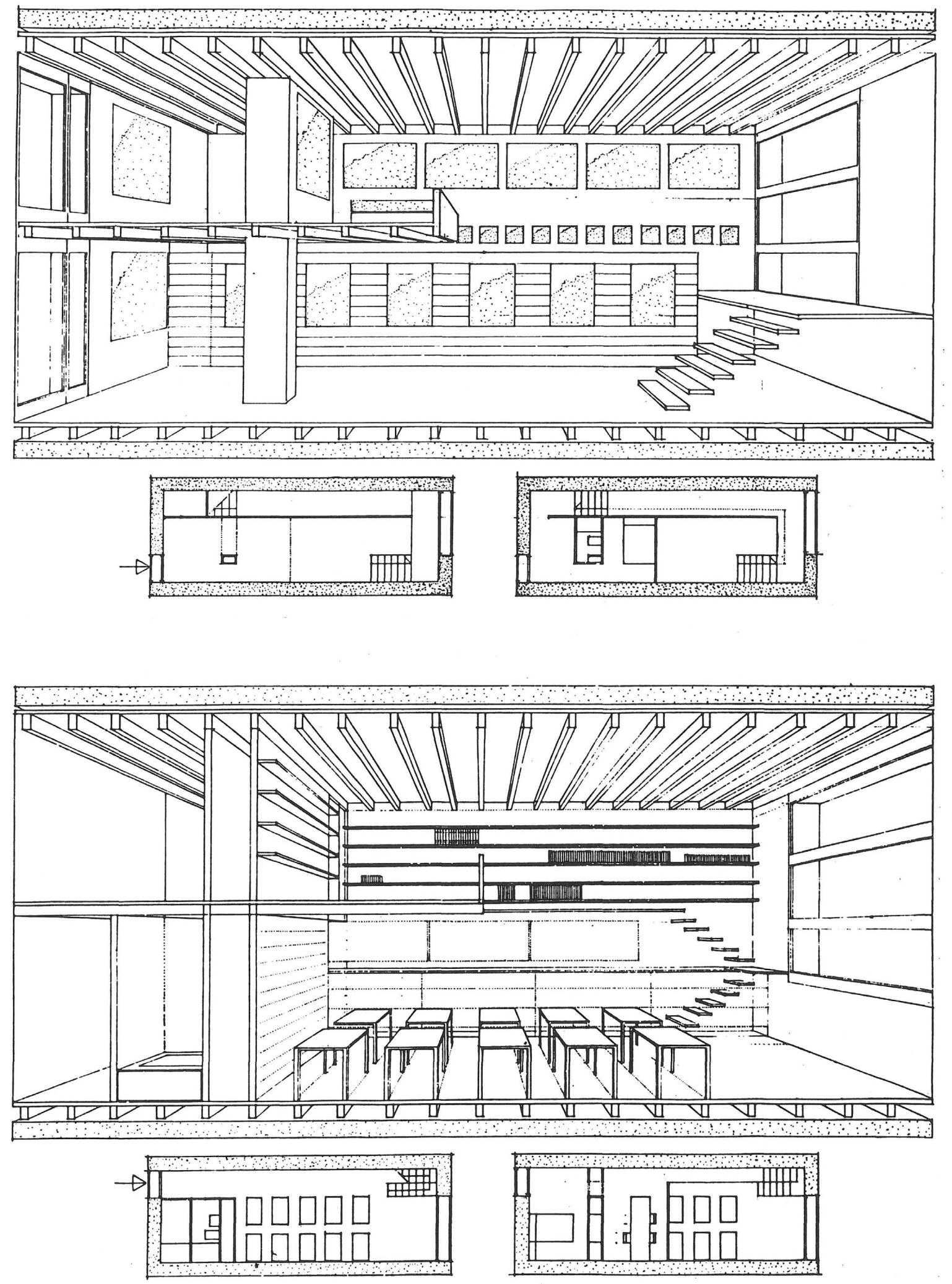

Fig. 25 b. Locales habitables adaptados a usos atípicos. 


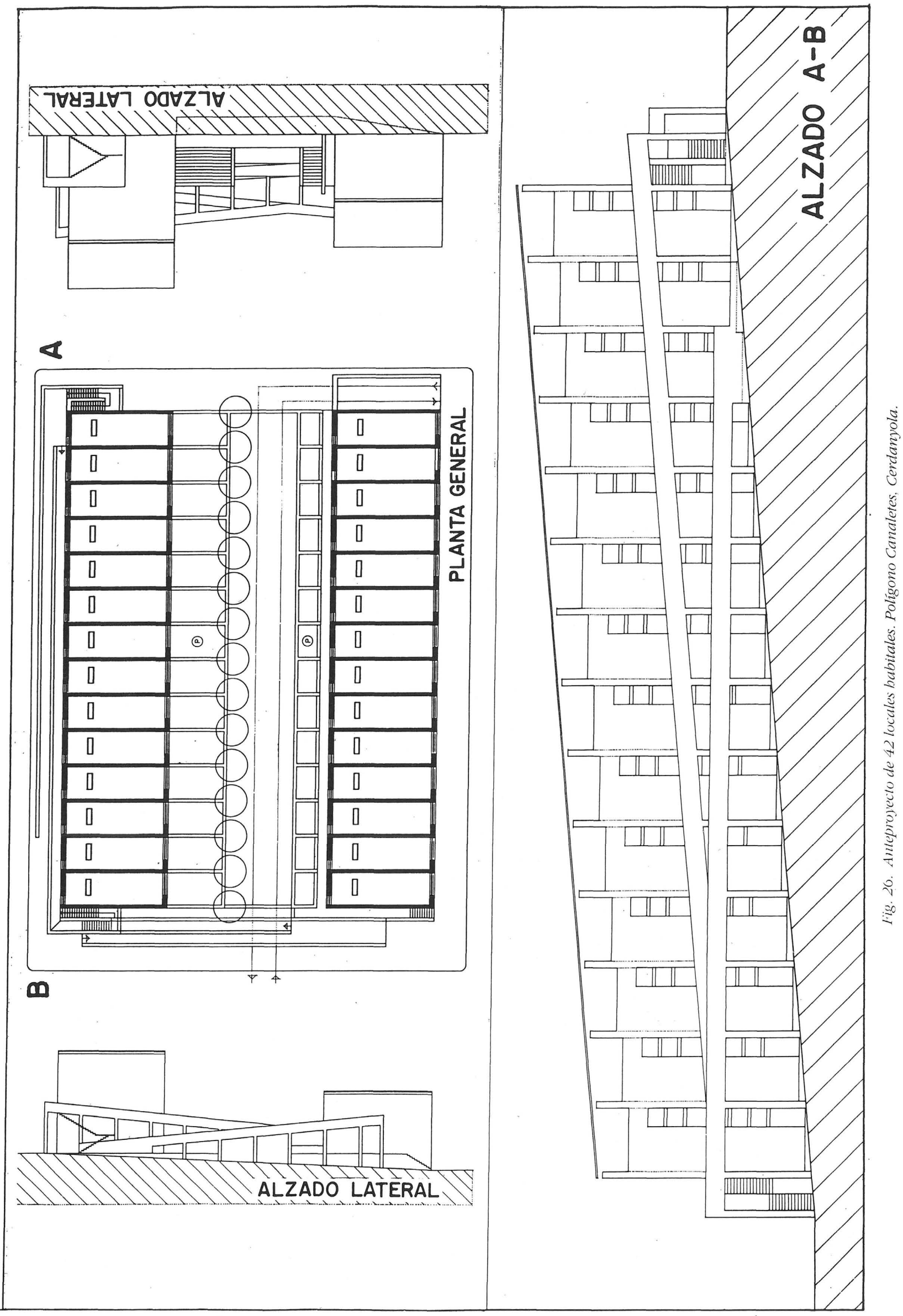




\section{Conclusiones}

Las viviendas que se construyen en la actualidad, tanto de protección pública como de promoción privada, repiten muy pocos tipos, resultan muy caras y no responden en muchos casos a la composición familiar.

Sin embargo, tanto la arquitectura culta como la tradicional, así como algunas de las experiencias que se desarrollan en la actualidad, demuestran las posi- bilidades de las variaciones tipológicas y las oportunidades de intervención.

Por ello se propone un prototipo de contenedor vacío, asequible y adaptable, que se pueda completar o no de acuerdo con el poder adquisitivo y las necesidades del usuario al que va destinado. Superponiendo contenedores, se forman conjuntos de "locales habitables" urbanos que se completan con los espacios de acceso y transición.

\section{BIBLIOGRAFÍA}

- B. Biermann: "Indlu. The domed dwelling of the Zulu"; en Shelter in Africa, P. Oliver, ed.; Barrie \& Jenkins, London; pp. 96 a 105, 1971.

- W. Boesiger \& O. Stonorov: "Le Cobusier Oeuvre complète, vol. 1-1910-1929", Les Éditions d'Architecture, Zurich, 1964.

- C. Davies: The work of Michael Hopkins and Partners, Phaidon Press Limited, London, 1993.

- A. Elliott: The Zulu traditions and culture, Struik Publishers, Cape Town, 1986.

- M. Fossas Pi.: Cartuja de Montalegre, Asociación de Arquitectos de Cataluña, Barcelona, 1884

- G. Goodwin: A bistory of Ottoman Architecture, Thames and Hudson, London, 1971

- P. Groenendijk \& P. Vollaard: Guide to modern architecture in the Netherlands, Uitgeverij 010 Publishers, Rotterdam, 1987.

- N. J. Habraken: Supports. An alternative to mass housing, The Architectural Press, Londron, 1972.

- S. \& M. Hirschi: L'architecture au Yemen du Nord, BergerLevrault, Paris, 1983

- H. Kuper: The architecture of Swaziland, The Architectural Review, julio, pp. 20 a 24, 1946.

- A. Lüchinger: Herman Hertzberger 1959-86, Arch-Edition, Den Haag, 1987
- Llorens \& Soldevila: "Viviendas económicas realizadas con bloques de hormigón. Experiencias y prototipos", Informes de

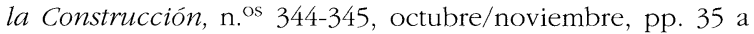
43, 1982.

— Llorens \& Soldevila: "La casa Riera de Alella. Una vivienda experimental de bloque de mortero. España", Informes de la Construcción, vol. 41, n. ${ }^{\circ}$ 406, marzo/abril, pp. 49 a 62, 1990.

- E. Massip: Habitatges experimentals 1971-1994- A. SoldevilaJ. I. Llorens, arq., Edicions UPC. Barcelona, 1994.

- E. Muhle: "La arquitectura rural de Ibiza como forma de construcción aglutinada", Publicaciones de la Delegación en Ibiza del Colegio de Arquitectos de Baleares, n. ${ }^{\circ} 4$ y 5, mayo, pp. 44 a $87,1982$.

- J. Nouvel \& J. M. Ibos: "Nîmes-Le quartier Nemausus", L'Arcbitecture d'Aujourd'bui, n. ${ }^{\circ}$ 252, septiembre, pp. 2 a 10, 1987.

- J. Rohe: "Wohnhaus in Lyon-Vaise", Baumeister, noviembre, pp. 52 a 55,1990

- K. Tetlow, 1992: "Designing for AIDS", Architecture, marzo, pp. 85 a $92,1992$.

- Varios autores: "Spécial Hollande", L'Architecture d'Aujoud'bui, n. ${ }^{\circ}$ 257, junio, 1988.

— Varios autores: "Holanda doméstica", A \& V Monografías de Arquitectura $y$ Vivienda, n. ${ }^{\circ}$ 19, 1989.

- U. Vogt - Göknil: Turquia otomana, Ediciones Garriga, S.A Barcelona, 1965 